\title{
High Accuracy Modelling of Hybrid Power Supplies
}

\author{
Valeria Boscaino and Giuseppe Capponi \\ University of Palermo \\ Italy
}

\section{Introduction}

This chapter proposes a modelling approach based on the PSIM/Simulink co-simulation toolbox for hybrid power supplies, featuring high accuracy. Hybrid source performances are fully tested during behavioural simulations. The importance of high-accuracy modelling is investigated and modelling guidelines for both power sources and load are given for further applications. The Simulink model is analyzed and the efficiency of the proposed approach is verified by the comparison between simulation and experimental results.

In the last few years, hybrid power supplies are investigated for a wide variety of application areas: two primary sources are coupled to take advantages of both, overcoming their drawbacks. The growing interest in hybrid sources is mainly due to the spread of fuel cells.

Fuel cells are renewable energy sources, fed by an external fuel and thus potentially infinite source of energy. The fuel cell supplies power until the fuel is supplied to, thus ensuring potentially infinite life cycle to each power load. Automotive, residential and portable electronics are only a few examples of fuel cells application areas. Powering a portable electronic device by a fuel cell is still a challenge for the scientific world. With the aid of fuel cells, the full portability is achieved: electronics devices could be recharged by simply replacing the fuel cartridge instead of being connected to the power grid. Further, fuel cells ensure the highest energy density allowing higher and higher device run time. Yet, portable devices feature a pulsed power consumption profile which depends on the user-selected function. The required peak power is usually higher and higher than the average power. Since the response of fuel cells to instantaneous power demands is relatively poor, innovative solutions are investigated to take full advantage from the fuel cell use. The goal is to couple the fuel cell with a high power density component. The instantaneous peak power is supplied by the high power density component while the average power is supplied by the fuel cell itself. Specific power management algorithms for active power sharing are required. Life-cycle and transient response are directly controlled thus leading to a close dependence of the power management control algorithms on the related application and power load. In the last few years, authors experienced the importance of accurate modelling of both power source and load to evaluate the system performances since the simulation step. The efficiency of power management algorithms is ensured by the high accuracy of source, power load and power management system modelling. 
The choice of a powerful simulation environment is a key step for a successful conclusion of the overall design process. The power consumption profile of the specific load device should be deeply analyzed to ensure proper control algorithms. Load emulators best fit designers' requirements. During behavioural simulations, emulators allow the designer to virtually use the load device reproducing the effective power consumption profile. Hence, no assumptions are made on the load power consumption profile while designing the power management algorithms avoiding the risk of experimental failures.

Fuel cell modelling is a critical step since fuel cells are non linear devices whose performances are heavily affected by temperature, fuel pressure and voltage-current operating conditions. Since electro-chemical, physical and geometrical parameters are not readily available to applications engineers, a black-box approach is usually preferred to an analytical one. Both steady-state and dynamic behaviour should be accurately modelled in order to design an efficient power supply design. In this chapter, an accurate modelling approach is proposed.

As an application, a fuel cell - supercapacitor hybrid power supply for portable applications is designed and tested. The proposed system supplies a Digital Still Camera (DSC). Like any other portable device, the digital still camera behaviours as a pulsed load. Unlike the others, the power consumption profile features three possible standby modes (playback, photography and movie mode), each one requiring a specific average current value. The load power consumption profile is closely dependent on the user-selected function and thus unpredictable. Consequently, the DSC represents the worst-case portable device for hybrid power supply design and optimization. Note that accurate modelling is required for testing purposes only. Useful information about the DSC state is reproduced by sampling the supply voltage. The power load, a Fujifilm S5500 Digital Still Camera is modelled in Simulink environment with the aid of the Stateflow toolbox. A user-interactive interface is provided. During behavioural simulations, the designer is able to select a specific DSC function and the corresponding power consumption profile is emulated. The fuel cell is modelled in Simulink environment. The architecture and modelling technique is suitable for each fuel cell type and power level. The proposed fuel cell model has been implemented by authors in several simulation environments like PSIM, Simulink and PSPICE and further implementations are readily available in literature. Yet, authors suggest the Simulink implementation to achieve low-complexity, high accuracy and the highest processing speed. On the basis of the Simulink model, a FPGA-based fuel cell emulator has been realized. With the aid of the fuel cell emulator, preliminary tests could be performed saving hydrogen reserve. A circuit implementation of the analog controller in PSIM environment is proposed. PSIM by Powersim Inc. is a circuit simulation software oriented to power electronics systems. Furthermore, a Matlab/PSIM co-simulation tool allows behavioural simulation in a mixed environment. In the basic package, PSIM consists of two programs: PSIM Schematics, full-featured schematic-entry program and SIMVIEW, advanced waveforms viewer software. As soon as the PSIM schematic is built, the designer is able to start the co-simulation procedure. In PSIM Elements/Control Library, the SimCoupler Module is provided for Matlab/Simulink co-simulation. Simulink input and output nodes are available. The Simulink input nodes receive values from Simulink and behaviour as voltage sources while the output nodes send values to Simulink. Input and output nodes can be placed in the PSIM schematics according to co-simulation requirements. After generating the circuit netlist in PSIM environment, the PSIM procedure for system cosimulation is completed. In Simulink, the SimCoupler block can be added to the existing 
Simulink model and linked to the PSIM netlist file by the block parameter box. The SimCoupler block now behaviours as a Simulink subsystem showing input and output ports as specified in the corresponding PSIM schematic: the Simulink output nodes are the subsystem input ports and the Simulink input nodes are the subsystem output ports. The PSIM schematic is simulated as an integral part of the active Simulink model. The efficiency of the Simulink-based modelling technique is shown by the comparison between simulation and experimental results.

\section{Hybrid power supply architectures}

Hybrid power sources have received a great deal of attention in the last few years and they are considered the most promising source of energy for portable applications. Two basic sources are coupled: a high energy density and a high power density source. The goal is to optimize the power and energy performances of the composite power source. Each basic source supplies the load current under a specific working condition, as steady-state or transient, according to its own stand-alone performances. The high energy density source, i.e. fuel cell, supplies the load current under steady-state. Simultaneously, under a load transient the high power density component, i.e. battery or supercapacitor, supplies the load with the difference between the instantaneous and the steady-state load current. The controller is accurately designed to correctly manage the power flow between primary sources and load. If properly controlled, the hybrid source is neither influenced by the transient response of the high energy density source nor by the running time of the high power density source. If compared with stand-alone basic sources, the hybrid source shows longer running time, faster transient response, higher power and energy density.

In literature, battery-ultracapacitor or fuel cell-battery power supply systems are presented (Gao \&Dougal, 2003; Alotto et al., 2008). Coupling a battery and an ultracapacitor yields higher specific power than a battery-alone source and higher specific energy than an ultracapacitor-alone source. In the meantime higher running time is achieved. Research on battery/ultracapacitor hybrids has been actively carried out for electric vehicles, portable electronics, weapon systems, as well as for industrial applications.

In literature hybrids are classified in active and passive sources. Direct coupling is a passive hybrids feature while in active hybrids a DC-DC converter is interposed between the two basic sources. Several advantages are brought by the DC/DC converter. A detailed comparative analysis of a battery/supercapacitor hybrid in passive and active configuration is reported in (Gao \& Dougal, 2003). The active hybrid configuration ensures an increase in power capability, a better regulation of the output voltage, a minimization of the current ripple and a reduction of the system weight and volume. If a capacitor based hybrid is considered, since the voltage of the two basic sources may be different, the capacitor array size could be designed independently of the other primary source. The DC-DC converter plays an important role in regulating the output voltage and making the voltage of the two basic sources independent of each other. The active hybrids ensure higher power capability than passive hybrids since the power sharing is directly controlled by the switching converter. Further, in active hybrids the output voltage is independent of the discharge curve of its stand-alone sources. In battery-based hybrids, the DC/DC converter can also act as a battery charger, leading to a decrease in system cost and weight.

Yet, all described hybrid systems are designed and tested with regular pulsed load, featuring a square wave current profile. The frequency and width of the current profile are 
usually assumed as design ratings by control algorithms, even if these assumptions are not verified by commercial devices. If tested with commercial devices, these algorithms would lead to an accidental turning-off or alternatively to a weak optimization of the hybrid power source in terms of both running time and power capability. A fuel cell/supercapacitor active hybrid system supplying a digital still camera is presented. A buck converter is interposed between the primary sources. The specific load device affects system ratings and the architecture of the hybrid source but not the control algorithm. Even under stress, an accidental turning-off is avoided. A high-accuracy model is proposed for both power sources and load. The importance of modelling is confirmed by the comparison between simulation and experimental results.

\section{The importance of measurements}

The importance of accurate modelling is extensively analyzed in literature. A detailed analysis of several modelling techniques is reported in (Liu, 1993). Measurement-based models are here proposed for both power source and load. Critical features are accurately highlighted and characterized by well-defined measurements. Designers accurately plan the measurement stage to achieve the best accuracy as well as the lowest complexity. Since the modelling approach can be efficiently applied to other devices, performed measurements are described for further applications. The model accuracy is closely related to the experimental setup. The goal is to minimize the difference between the experimental and simulated response to the same input which is usually referred to as the model error. The least the model error, the more efficient the model is. Under ideal conditions, the error is null and the model perfectly matches the effective behaviour of the device under test (DUT). A source of error relies in the model architecture. For example, a highly non-linear device is usually modelled by a linear model leading to an intrinsic source of error. Further, the model error is affected by the accuracy of measures since the model parameters are estimated from a finite and noisy data set. The proposed models are based on high-accuracy measurements and a non-linear model is proposed despite of the model complexity. Tunable parameters are provided for further applications.

\subsection{Measurements on the load device}

The digital camera behaviours as a pulsed load whose power consumption profile highlights two critical features: the power consumption profile is unpredictable since it depends on the user-selected function and the peak power is usually higher and higher than the average power drawn by the power supply. The power source life cycle and fuel consumption as well as the tolerance window on the output voltage are only a few performance indicators of the hybrid power supply. Hence, a complete analysis is performed to identify critical working conditions. The goal is to reproduce the power consumption profile of the load device and its correlation with the running function. The proposed model allows the designer to virtually use the digital camera during behavioural simulations. The designer is able to select a function obtaining the required consumption profile. The supply current of the digital camera has been monitored under function running. Experimental data are stored in look-up-tables and included in the Simulink model. Samples of measures are here discussed. The DSC features three stand-by modes of operation playback, photography and movie mode. Each mode can be maintained indefinitely active even if no function is running. The standby current is constant and 
closely related to the actual mode: $180 \mathrm{~mA}$ for playback mode, $330 \mathrm{~mA}$ for photography mode and $440 \mathrm{~mA}$ for movie mode. Each available function requires a pulsed current over the entire function run time. The load current profile under turning-on in playback mode is shown at the left in Fig.1. At the end of function transient, the required load current is strictly constant at $180 \mathrm{~mA}$. Yet, during the transient, the peak current reaches $486 \mathrm{~mA}$ and the run time is equal to 1.24s. The load current profile under the zoom function in playback mode is shown at the right in Fig.1. The transient time is equal to $88.4 \mathrm{~ms}$ and the peak current reaches $351 \mathrm{~mA}$. The average current value over the function transient time is equal to $269 \mathrm{~mA}$. If compared with turning-on in playback mode, the transient time is quite short and the peak current value is quite similar to the average current value. Hence, the zoom function is not critical for the hybrid power supply.

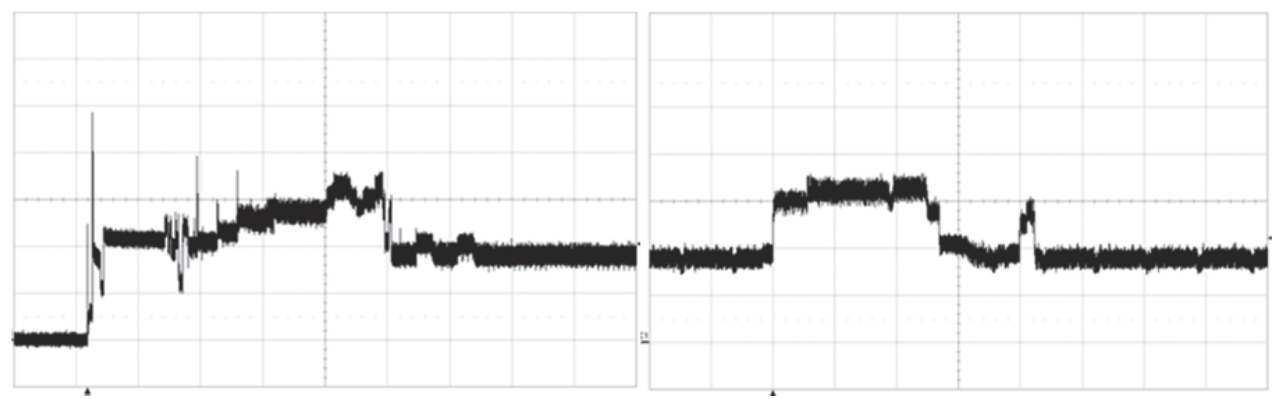

Fig. 1. At the left, the DSC current profile under turning-on in playback mode $(100 \mathrm{~mA} / \mathrm{div})$ is shown. Time base is set to $200 \mathrm{~ms} /$ div. At the right, the DSC current profile under zoom function in playback mode $(100 \mathrm{~mA} / \mathrm{div})$ is shown. Time base is set at $20 \mathrm{~ms} / \mathrm{div}$.

The load current profile under turning-on the DSC in photography mode is shown at the left in Fig.2. At the end of transient the current is constant at $330 \mathrm{~mA}$ which is the standby current of the photography mode. Yet, under function running, the load current reaches a $611 \mathrm{~mA}$ peak value and the transient time is equal to $4.6 \mathrm{~s}$. The load current profile required for taking picture without flash is shown at the right in Fig.2. The transient time is equal to 2.9s. The peak current value is equal to $716 \mathrm{~mA}$ and the average current over the transient time is equal to $443 \mathrm{~mA}$. The load current under movie mode selection is shown at the left in
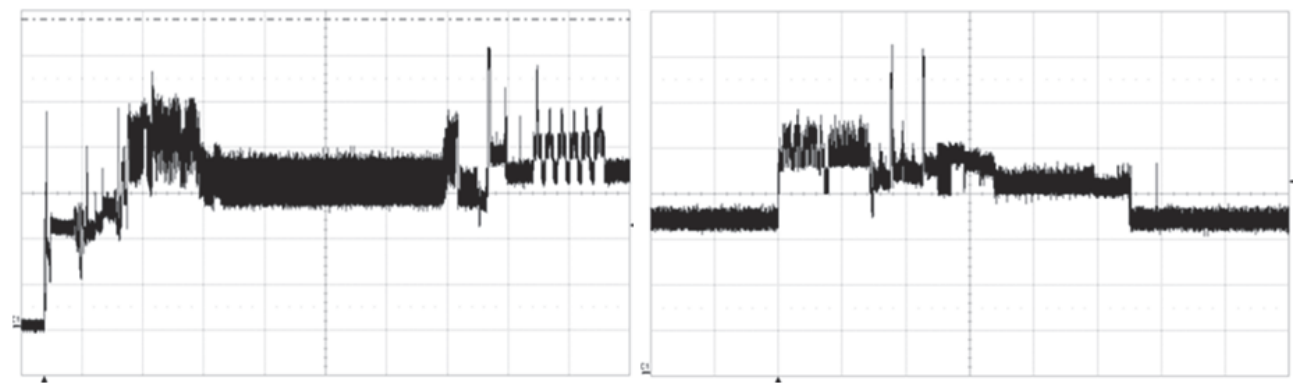

Fig. 2. At the left, the DSC current profile under turning-on in photography mode $(100 \mathrm{~mA} / \mathrm{div})$ is shown. Time base is set to $500 \mathrm{~ms} / \mathrm{div}$. At the right, the DSC current profile under taking picture without flash $(100 \mathrm{~mA} / \mathrm{div})$ is shown. Time base is set at $500 \mathrm{~ms} / \mathrm{div}$. 
Fig.3. The peak current value is equal to $669 \mathrm{~mA}$ and the transient time is equal to $430 \mathrm{~ms}$. At the right, the load current under the zoom function in movie mode is shown. The transient time is $630 \mathrm{~ms}$ long and the current reaches a $691 \mathrm{~mA}$ peak value. Only a few examples are shown. The load current profile of each available function is monitored and collected data are stored to be used in the DSC model. Critical functions for the hybrid power supplies are identified by the transient time and the current peak value. The worst-case function features the highest current peak value and the longest transient time. The power management system should prevent an excessive supercapacitor discharge under the worst-case.
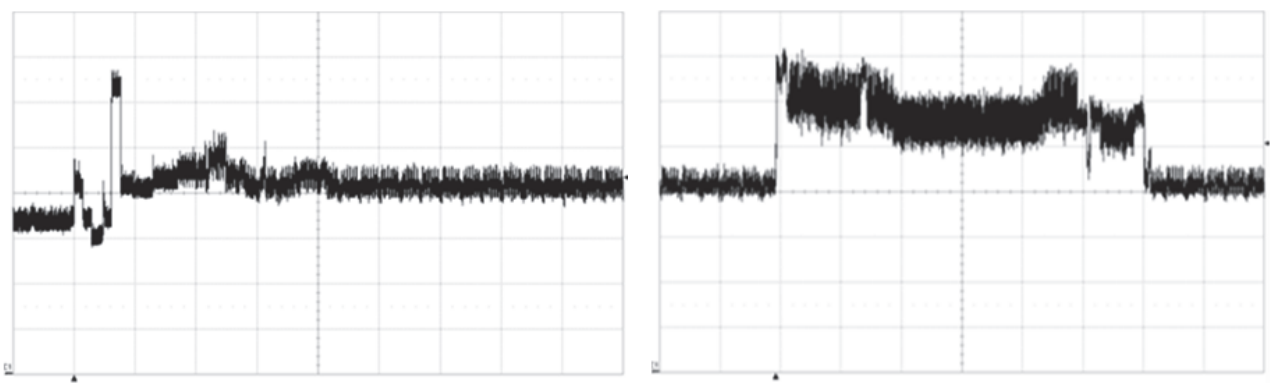

Fig. 3. At the left, the DSC current profile under the transition from photography to movie mode $(100 \mathrm{~mA} /$ div $)$ is shown. Time base is set to $100 \mathrm{~ms} /$ div. At the right, the DSC current profile under zoom function in movie mode $(100 \mathrm{~mA} / \mathrm{div})$ is shown. Time base is set at $100 \mathrm{~ms} /$ div.

\subsection{Measurements on the fuel cell}

A measurement-based fuel cell model is proposed. The model matches the steady-state and dynamic behaviour of the stack under test, including temperature effects. The stack is accurately characterized to achieve high-accuracy. Even if a 10W, 9V Proton Exchange Membrane (PEM) fuel cell stack is tested, the model can be efficiently applied to each fuel cell type and power level. Steady-state measurements are performed. Iso-thermal steady-state $\mathrm{V}-\mathrm{I}$ curves are measured at several temperature values ranging from $20^{\circ} \mathrm{C}$ to $40^{\circ} \mathrm{C}$ by $5^{\circ} \mathrm{C}$ step. Experimental data are collected and averaged over multiple measures. Average iso-thermal steady-state curves are plotted in Fig.4. A current limit is shown for each steady-state curve. If the fuel cell current overcomes the limit a flooding event occurs: hydrogen is not enough to produce the required current. Hence, water is sucked into the stack obstructing the membrane pores. A flooding event leads to an instantaneous voltage drop and the device is immediately turned-off. The limit is a function of the operating temperature since the reaction speed increase with increasing temperature. The fuel cell current is directly controlled by the power management system avoiding the flooding risk. The frequency response analysis is performed to model the dynamic behaviour of the stack under test. The impedance function is measured under linear conditions. A sinusoidal current is forced and the magnitude of the sinusoidal voltage is measured. The stack non-linearity is neglected while measuring the transfer function. Non-linear effects of operating temperature are neglected by performing measurements at a fixed temperature value of $30^{\circ} \mathrm{C}$. Further, the steady-state curve nonlinearity is neglected by a small-signal approximation. The average current value is fixed at $600 \mathrm{~mA}$ and a sinusoidal signal of $200 \mathrm{mAp}$-p is forced. In the fixed current region, at $30^{\circ} \mathrm{C}$, the non-linearity of the steady-stare curve could be neglected. The goal is to model the impedance 
transfer function by a dynamic admittance which is connected in parallel with the steady-state model. The equivalent resistance of the steady-state model is then connected in parallel to the dynamic impedance. If the operating condition changes, the equivalent resistance of the steady-state model changes and the model is able to fit the dynamic behaviour of the stack under test. Experimental results validate the modelling technique. For further details, please refer to (Boscaino et al., 2009b). The Bode plot of the impedance magnitude is shown in Fig.5. On y-axis a linear scale is used. Since the system square wave response analysis shows no time constant lower than $1 \mu \mathrm{sec}$, the magnitude of the transfer function is assumed constant for high frequency values.

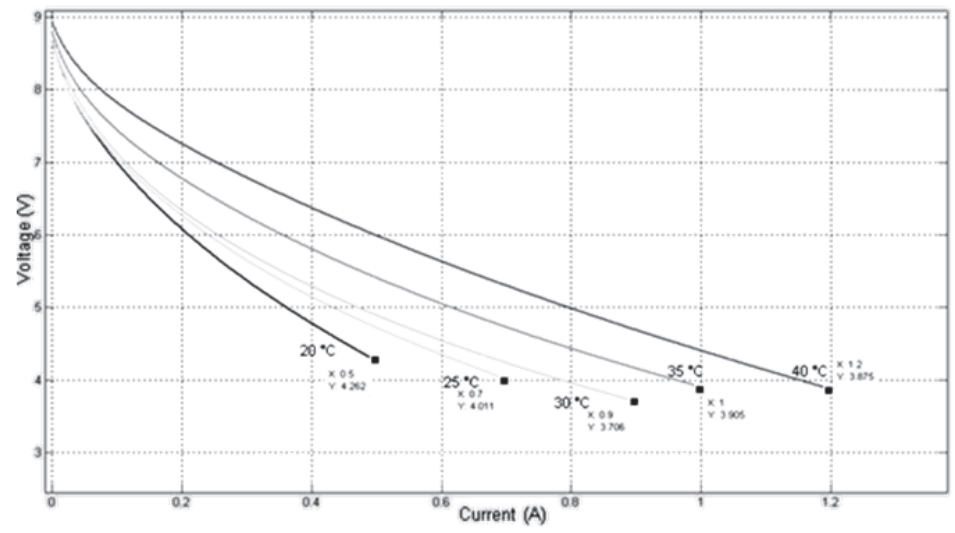

Fig. 4. Average iso-thermal steady-state curves.

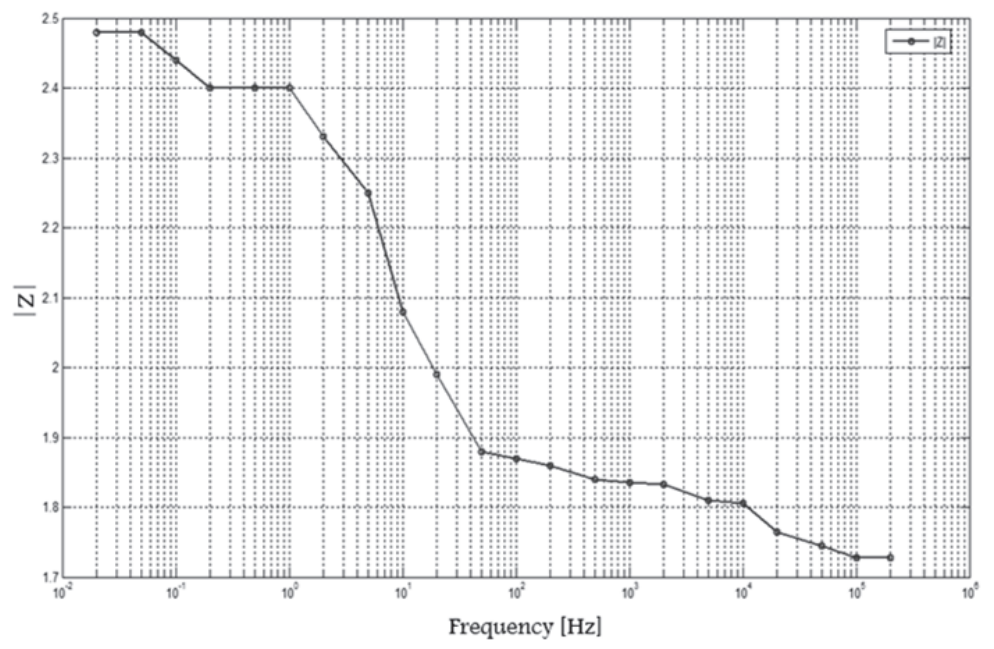

Fig. 5. Bode plot of the impedance magnitude.

Measurements are performed up to $200 \mathrm{kHz}$. Temperature effects on the fuel cell performance are included in the fuel cell model. Further, the model reproduces the stack temperature as a 
function of the fuel cell current. The thermal response of the fuel cell is monitored as shown in Fig.6. Thermal measurements are performed by monitoring the current profile and the corresponding temperature profile.
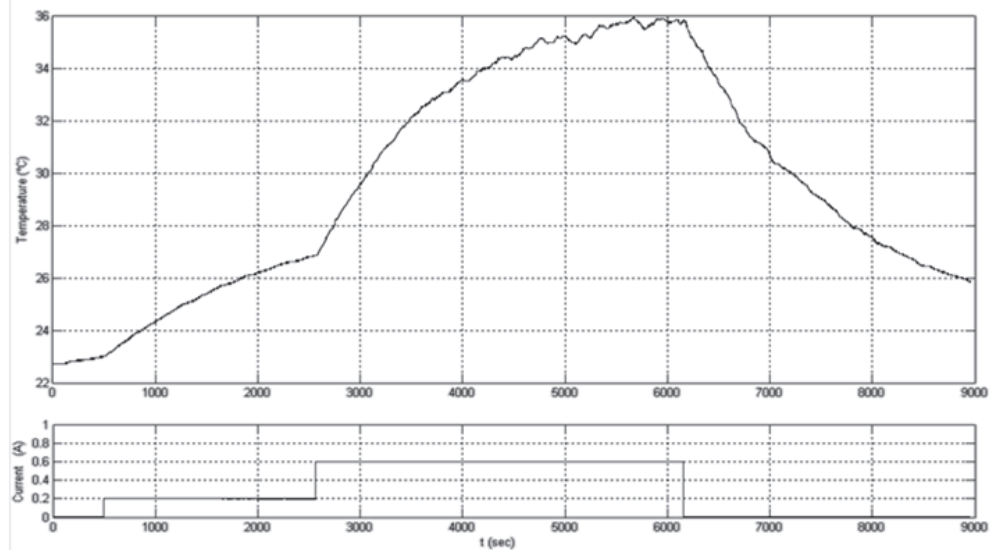

Fig. 6. At the top, the thermal response of the fuel cell stack. At the bottom, the corresponding current waveform.

\section{The simulink model}

A fuel cell - supercapacitor hybrid power supply is designed. The active hybrid source is modelled by a PSIM schematic as well as the power management control system. The primary source and the power load are modelled in Simulink environment. The top level model is shown in Fig.7. The SimCoupler block simulates the power management system implemented by a PSIM schematic which is fed by the fuel cell voltage and the load current signals and generates the output voltage of the hybrid supply.

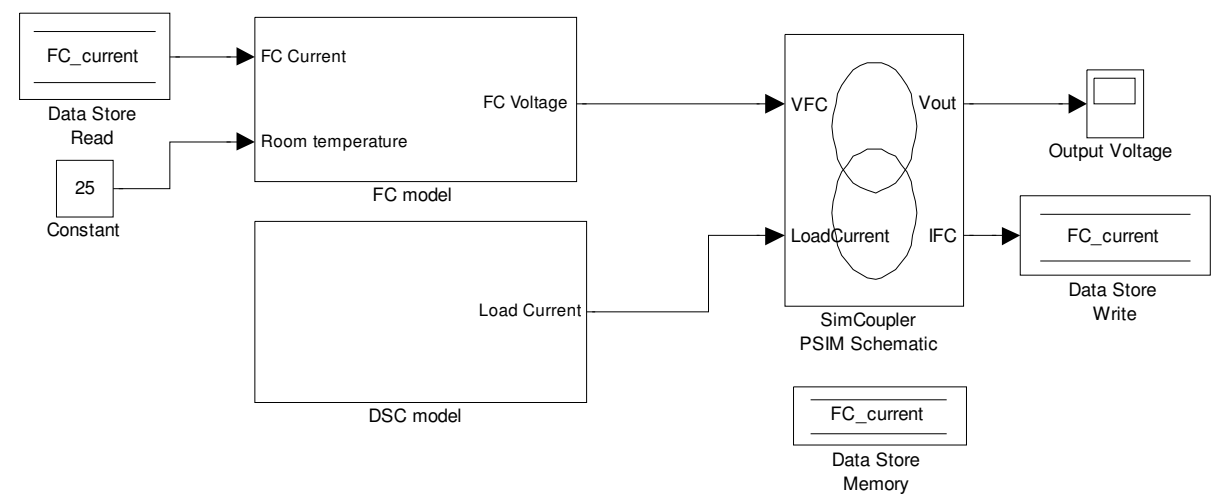

Fig. 7. Hybrid power supply model.

The fuel cell current is sensed within the PSIM schematic. The fuel cell current signal feeds the fuel cell subsystem by the means of data stores. In order to enable the signal 
analysis in Simulink environment too, the output voltage is considered as a Simulink Output Node.

\subsection{The fuel cell model}

The fuel cell model is shown in Fig.8. The stack voltage is generated as a function of the fuel cell current. The room temperature is introduced as an external parameter. The steady-state and dynamic sections are highlighted. The steady-state behaviour, including temperature effects, is modelled by the Steady-state Section. The dynamic section models the transient response by the means of an admittance which is connected in parallel to the steady-state model. Hence, the parallel connection is modelled by feeding the Dynamic Section by the output voltage and introducing a current node at the input of the Steady-State Section. By the means of data stores, the fuel cell voltage is stored as an output of the Steady-State Section and then read by the Dynamic Section as an input signal. The Steady-State Current is obtained by adding the Dynamic Current to the external fuel cell current.



Fig. 8. The fuel cell model.

The steady-state section is modelled as shown in Fig.9. Note that the stack temperature is quite different from the room temperature. The room temperature is an external signal while the stack temperature is reproduced as a function of the fuel cell current by the temperature subsystem. The steady-state subsystem reproduces the stack voltage as a function of the fuel cell current $i$ and the reconstructed temperature value $T$. The steadystate subsystem is modelled as shown in Fig.10. The steady-state voltage at a temperature $T$ under a current $i$ is given by:

$$
\mathrm{V}(\mathrm{i}, \mathrm{T})=\mathrm{V}(\mathrm{i}, \text { Tref })+\mathrm{c}(\mathrm{i}, \mathrm{T}-\text { Tref })
$$

where $V(i$, Tref $)$ is the steady-state voltage at a nominal temperature of $30^{\circ} \mathrm{C}$ under a current $i$ and $c(i, T-T r e f)$ is the voltage correction term accounting for a temperature $T$ which is different from the nominal one.

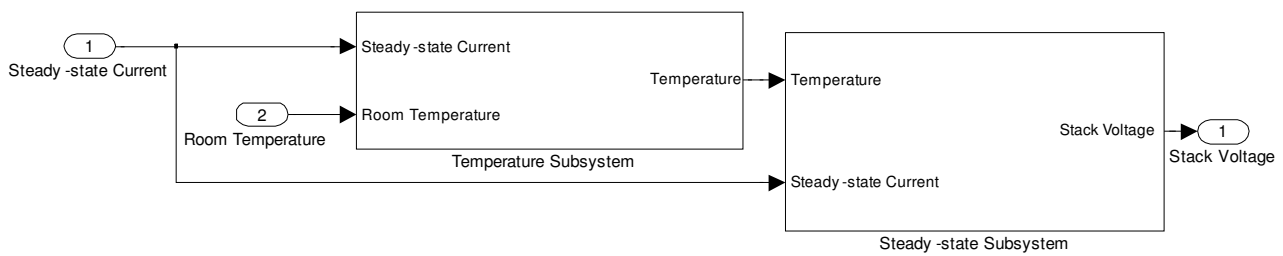

Fig. 9. The steady-state section model. 




Fig. 10. The steady-state subsystem model.

The term $V(i$, Tref $)$ is the output signal of the so-called Iso-thermal steady-state subsystem while the correction term is generated by the Correction subsystem. No matter how many and which the involved physical, geometrical and chemical parameters are, the iso-thermal steady-state curve at the reference temperature is fitted by the law:

$$
V(i, \operatorname{Tr} e f)=A-B \cdot \ln \left(1+\frac{i}{C}\right)-D \cdot e^{\frac{i}{E}}
$$

where $\mathrm{A}, \mathrm{B}, \mathrm{C}, \mathrm{D}, \mathrm{E}$ are the iso-thermal steady-state model parameters. Model parameters are obtained by fitting the experimental data with the aid of the Curve Fitting Tool which is available in MATLAB environment. The Iso-thermal steady-state subsystem is shown in Fig.11. The subsystem is fed by the Steady-state current and reproduces the stack voltage at the reference temperature of $30^{\circ} \mathrm{C}$. The A parameter is modelled by the constant block. Exponential and logarithmic terms are generated by the subsystems shown in Fig.12. According to (2), parameters B, C, D and E are modelled by proper Gain blocks which are introduced in the signal chain. The gain value is entered by the parameter box. Exponential and logarithmic functions are implemented by Math Function blocks which are readily available in the Simulink library browser.



Fig. 11. The iso-thermal steady-state subsystem model. 
The type of function is selected by the parameters box. The shift by 1 of the logarithmic argument is modelled by the Bias block. The shift constant is introduced by the block parameter box. Very complex functions, such as the logarithmic or exponential function are readily implemented by elementary blocks.
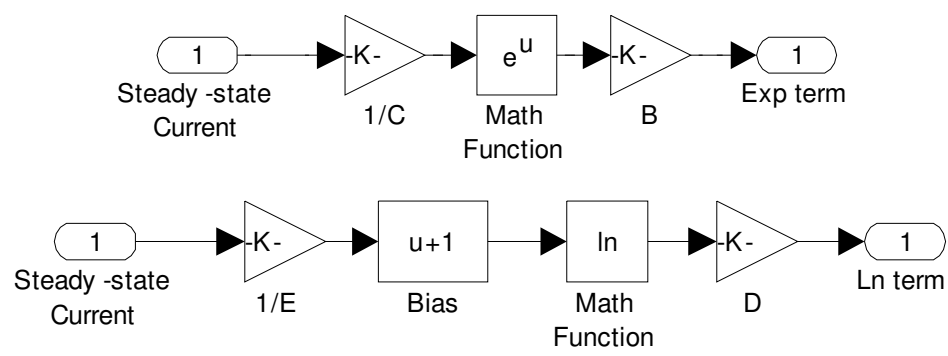

Fig. 12. The exponential and logarithmic subsystems.

The correction subsystem accounts for temperature effects. The subsystem is fed by the stack temperature and the fuel cell steady-state current, as shown in Fig.13.

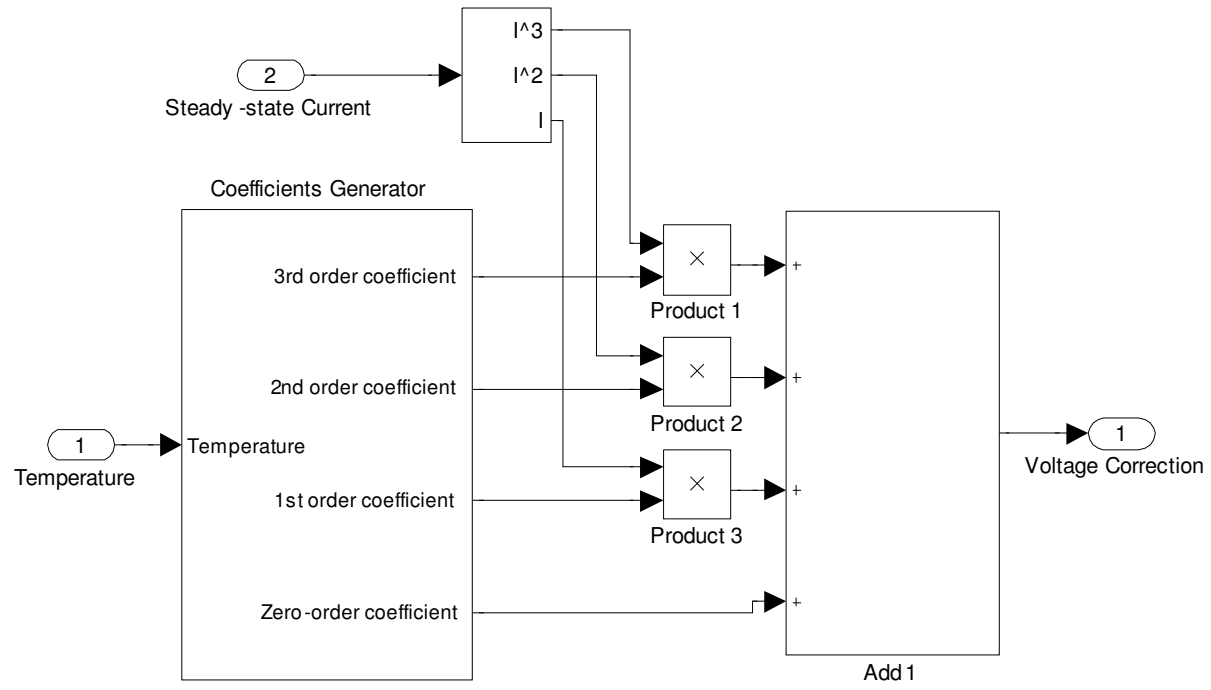

Fig. 13. The correction subsystem model.

According to (1) a set of average correction curves is obtained. If a point of the iso-thermal correction curve at the temperature $T$ is selected, the $x$-axis coordinate equals the fuel cell current $i$ and the $y$-axis coordinate the correction term $c\left(i, T-T_{r e f}\right)$. The correction subsystem is modelled by a bi-dimensional polynomial fitting of the average correction curves. A thirdorder polynomial is chosen for current-fitting while a fourth-order polynomial is chosen for temperature fitting. The correction curve at a temperature $T_{1}$ is fitted as a function of current by the polynomial law:

$$
C\left(i, T_{1}\right)=C_{0}\left(T_{1}\right) \cdot i^{0}+C_{1}\left(T_{1}\right) \cdot i^{1}+C_{2}\left(T_{1}\right) \cdot i^{2}+C_{3}\left(T_{1}\right) \cdot i^{3}
$$


where $\mathrm{C} 0, \mathrm{C} 1, \mathrm{C} 2$ and $\mathrm{C}_{3}$ are the polynomial coefficients. Each coefficient of the current polynomial is given by evaluating a fourth-order polynomial at the fixed input temperature. Coefficients at a fixed temperature $\mathrm{T}_{1}$ are given by:

$$
\begin{aligned}
& C_{0}=C_{0,0}+C_{0,1}\left(T_{1}-T_{r e f}\right)+C_{0,2}\left(T_{1}-T_{r e f}\right)^{2}+C_{0,3}\left(T_{1}-T_{r e f}\right)^{3}+C_{0,4}\left(T_{1}-T_{r e f}\right)^{4} \\
& C_{1}=C_{1,0}+C_{1,1}\left(T_{1}-T_{r e f}\right)+C_{1,2}\left(T_{1}-T_{r e f}\right)^{2}+C_{1,3}\left(T_{1}-T_{r e f}\right)^{3}+C_{1,4}\left(T_{1}-T_{r e f}\right)^{4} \\
& C_{2}=C_{2,0}+C_{2,1}\left(T_{1}-T_{r e f}\right)+C_{2,2}\left(T_{1}-T_{r e f}\right)^{2}+C_{2,3}\left(T_{1}-T_{r e f}\right)^{3}+C_{2,4}\left(T_{1}-T_{r e f}\right)^{4} \\
& C_{3}=C_{3,0}+C_{3,1}\left(T_{1}-T_{r e f}\right)+C_{3,2}\left(T_{1}-T_{r e f}\right)^{2}+C_{3,3}\left(T_{1}-T_{r e f}\right)^{3}+C_{3,4}\left(T_{1}-T_{\text {ref }}\right)^{4}
\end{aligned}
$$

where $\mathrm{Ci}, \mathrm{j}$ is the $\mathrm{j}$-th order coefficient of the temperature polynomial which gives the $\mathrm{Ci}$ coefficient of the current polynomial. Fig.14 shows the iso-thermal correction curves after the fitting operation as a function of the fuel cell current.

The Coefficients generator subsystem is fed by the temperature signal and generates the coefficients of the current polynomial $\mathrm{C}_{0}, \mathrm{C} 1, \mathrm{C} 2$ and $\mathrm{C}_{3}$ corresponding to the input temperature value. Then the current polynomial is evaluated at the input current value. The subsystem is modelled by elementary blocks of Simulink libraries.



Fig. 14. Iso-thermal correction curves after current fitting procedure.

The model of the Coefficients Generator subsystem is shown in Fig.15. Polyval blocks are introduced to model a polynomial. Coefficients are set by the parameter box.

Hence, the current polynomial coefficients are evaluated by the Coefficients Generator subsystem which is fed by the temperature value $T$. The coefficients are applied to evaluate the current polynomial at the input current value $i$.

The thermal section is modelled by fitting the fuel cell thermal transient response by the Parameters Estimation Toolbox which is available in MATLAB/Simulink environment. The temperature profile is reproduced by the Temperature subsystem as a function of the fuel cell current. The thermal response of the fuel cell is modelled as:

$$
a \frac{d T}{d t}=-\left(T-T_{\text {room }}\right)+g \cdot i+d \cdot i^{2}
$$


where $T$ is the absolute stack temperature, $T_{\text {room }}$ the ambient temperature and $i$ the total current.
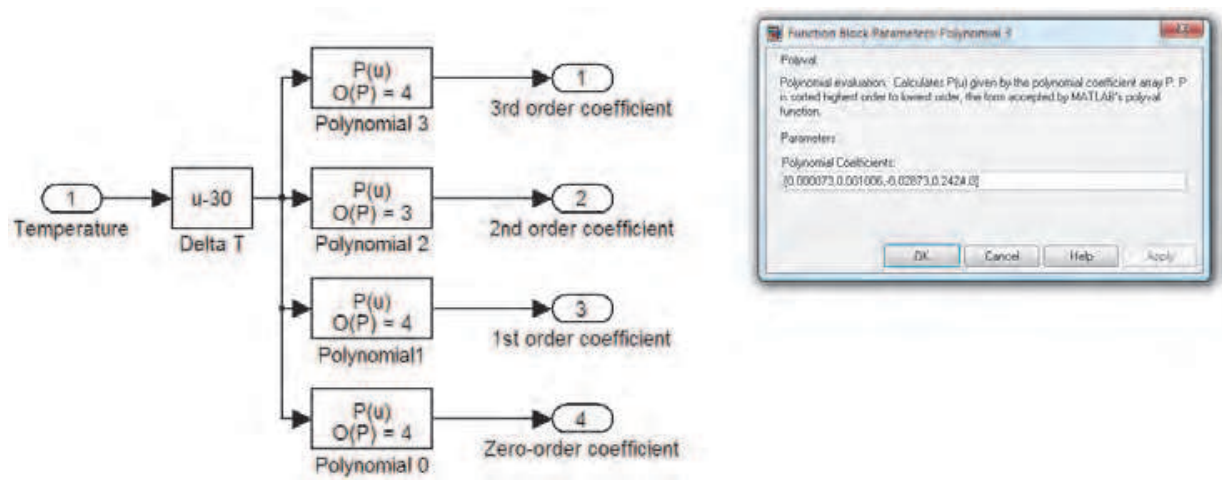

Fig. 15. The Coefficients Generator subsystem model.

The term $d i^{2}$ involves Joule heating to temperature $T$ and the term $g i$ models the evolved heat, the effects of the reaction rate and lost heat. Effects of room temperature are encountered by the first term in (5). Thermal model parameters $a, g$, $d$ are obtained by performed measurements with the aid of the Parameter Estimation Toolbox, which is available in Simulink environment. By Laplace transform, the (5) is solved as:

$$
\begin{gathered}
T(t)=T_{0} \cdot e^{-\frac{t}{a}+\frac{1}{a} \cdot e^{-\frac{t}{a}}} \cdot \int_{0}^{t} T_{\text {room }}(t) \cdot e^{\frac{\tau}{a}} \cdot d \tau+\frac{g}{a} \cdot e^{-\frac{t}{a}} \cdot \int_{0}^{t} i(\tau) \cdot e^{\frac{\tau}{a}} \cdot d \tau+ \\
+\frac{d}{a} \cdot e^{-\frac{t}{a}} \cdot \int_{0}^{t} i^{2}(\tau) \cdot e^{\frac{\tau}{a}} \cdot d \tau
\end{gathered}
$$

In Fig.16 the temperature subsystem model is shown. The temperature signal is generated by adding integral and exponential terms. Each elementary term of (6) is modelled by Simulink library blocks. The Clock block generates the simulation time $t$. Exponential terms are evaluated by the means of the time $t$ and the Math function block. The integral operator is modelled by the Integrator block.

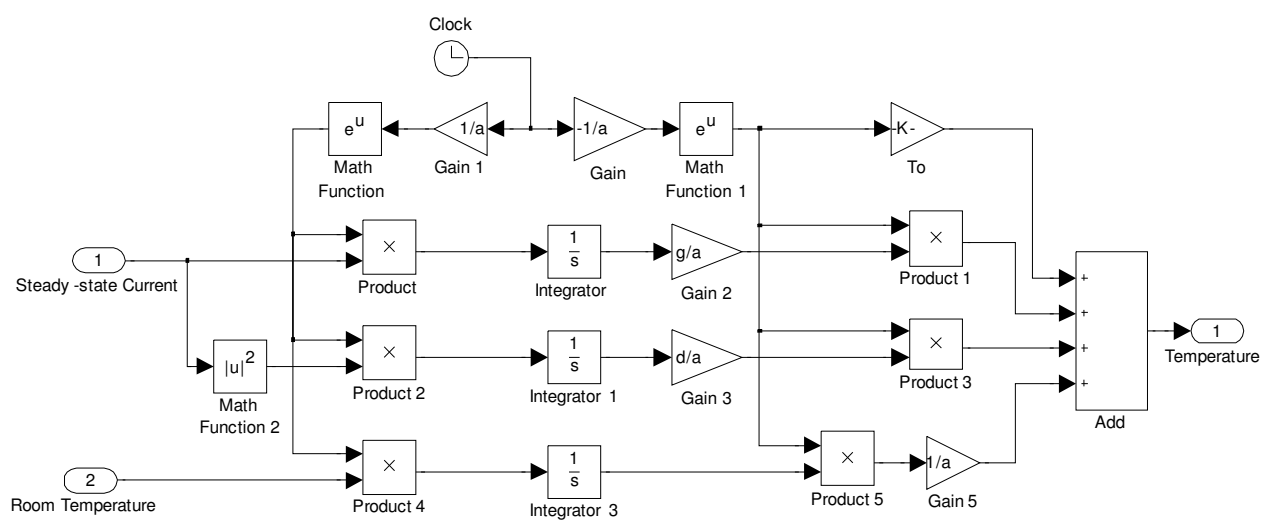

Fig. 16. The temperature subsystem. 
According to (5), the thermal response to a current step is given by:

$$
T(t)=T_{0}+\left(T_{\text {room }}-T_{0}+g \cdot I+d \cdot I^{2}\right)\left(1-e^{-\frac{t}{a}}\right)
$$

where $I$ is the current step final value, $T_{\text {room }}$ is the room temperature and To the initial temperature condition. A current step towards zero current leads to a thermal transient whose final value is the environment temperature $T_{\text {room }}$. According to (5), the thermal response to a current step towards zero current value is given by:

$$
T(t)=T_{0}+\left(T_{\text {room }}-T_{0}\right)\left(1-e^{-\frac{t}{a}}\right)
$$

By fitting the thermal response to a current step towards zero value, the $a$ parameter is obtained. The thermal response to the rising and falling-edge of a current step is monitored, obtaining $g$ and $d$ parameters.

As discussed, the dynamic subsystem models the impedance which is dynamically connected in parallel to the steady-state model. The approximated impedance transfer function is modelled by the Transfer Function library block, as shown in Fig.17. The dynamic voltage is obtained by subtracting the constant term of the steady-state model to the stack voltage. The dynamic current is generated by the transfer function block $\mathrm{Y}(\mathrm{s})$. The analysis of the model accuracy yields a maximum voltage error value of $0.2 \mathrm{~V}$, comparable to experimental data scattering. The thermal model error is limited to $1^{\circ} \mathrm{C}$. Authors suggest (Boscaino et al., 2009b) for further details.

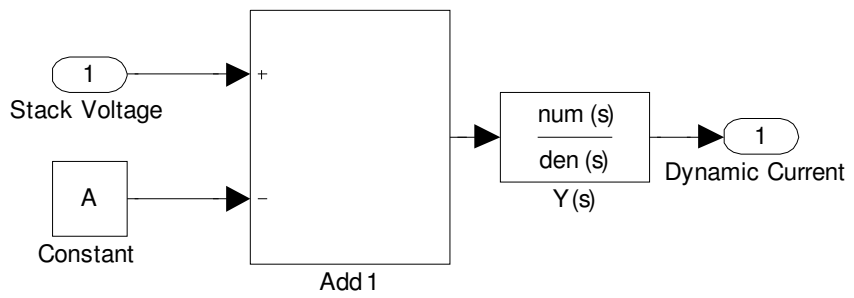

Fig. 17. The dynamic section model.

\subsection{The DSC model}

The load emulator is modelled in Simulink environment. Thanks to the powerful Stateflow toolbox a user-interactive model is implemented. During behavioural simulation, the designer is able to select a DSC function emulating the effective load device. The effective power consumption pattern corresponding to the actual user-selected function is generated by the load model. The designer is able to reproduce a random usage of the electronic load device.

No assumptions are made about the load current profile during behavioural simulations. System performances are already evaluated by computer simulations saving hydrogen reserve for preliminary tests and avoiding the risk of experimental fault conditions. The hybrid source life-cycle and fuel consumption could be tested as well as system stability and dynamic response.

The load device is modelled by a state machine: user-selections are modelled as events and the available functions are modelled as the finite states. The state-machine is implemented 
by the Stateflow toolbox which is available in Simulink library browser. The model is based on a Fujifilm S5500 digital still camera. Main sections of the DSC model are highlighted in Fig.18: User Interface, Mux and DSC subsystem. Manual switches are included in the User Interface section. Each manual switch is labelled by a specific DSC function. By acting on a manual switch, the designer generates events for the state-machine thus running the corresponding function. Scalar events are collected by the Mux subsystem into DSC subsystem input vector. In the DSC subsystem, the state-machine and the output section are modelled.

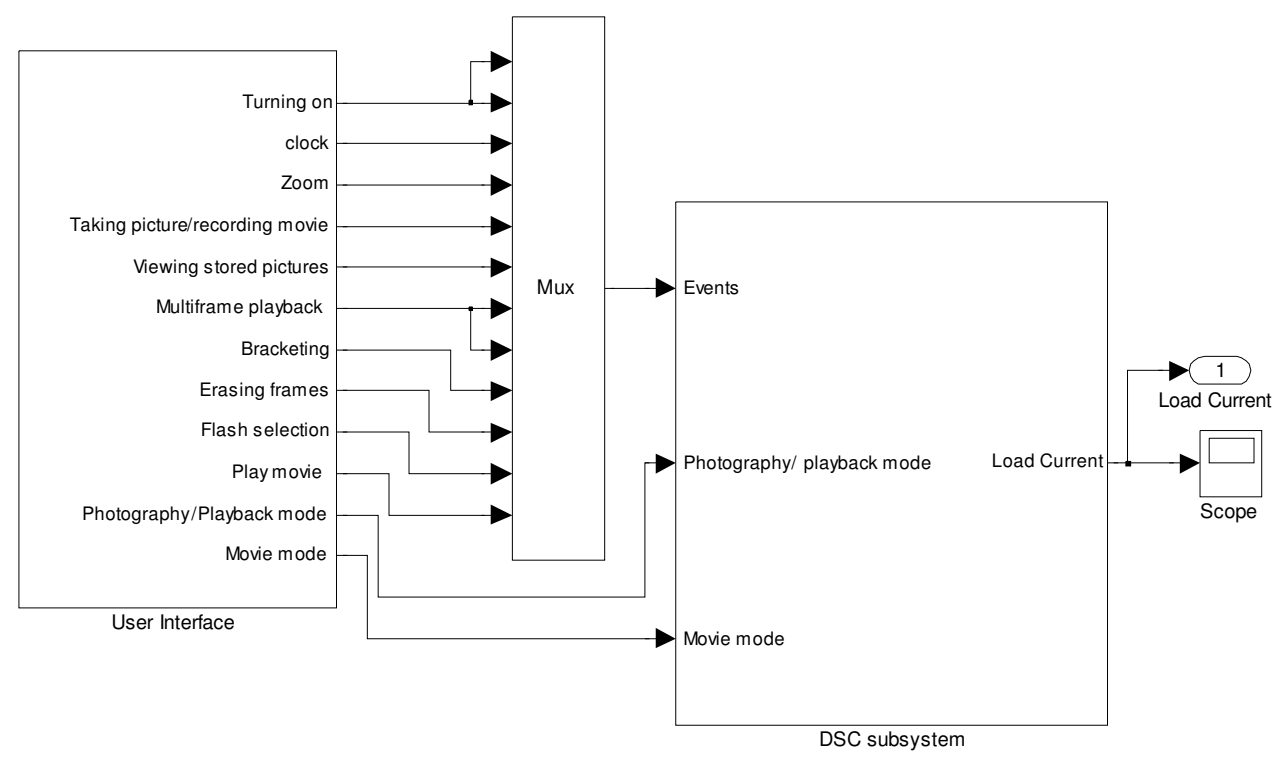

Fig. 18. MATLAB/Simulink DSC model.

The state-machine receives events and conditions. The event immediately triggers a state transition. Under the clock rising-edge conditions are verified thus enabling a state transition. Events and conditions are generated in the User-Interface subsystem as shown in Fig.19.

Manual switches are collected within the subsystems. Take a look to the Conditions subsystem shown in Fig.20. Photography or playback mode is selected by double-clicking on the corresponding manual switch. A condition for the state-machine is generated by the manual switch. If the condition is true, corresponding to the logic value 1 , the state-machine is driven toward the Photography Mode. Otherwise, the system is driven towards the Playback Mode. Even though events are generated instead of conditions, the Events subsystem features a similar architecture, as shown in Fig.21. End-user actions on the digital camera selector switch are marked as conditions while actions on buttons are marked as events. Each manual switch within the Events subsystems emulates a physical button of the digital camera under test. As shown Fig.22, the DSC subsystem is modelled by a state diagram and an output section. 




Fig. 19. The user-interface subsystem.
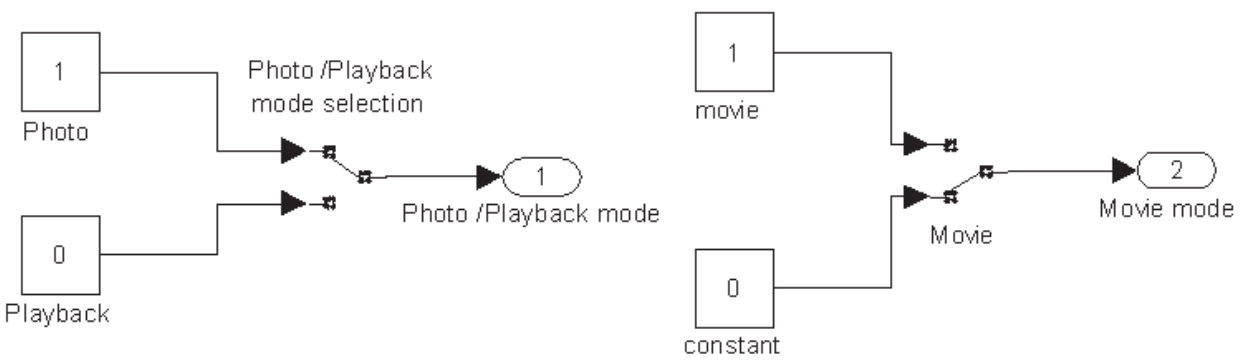

Fig. 20. Conditions. 


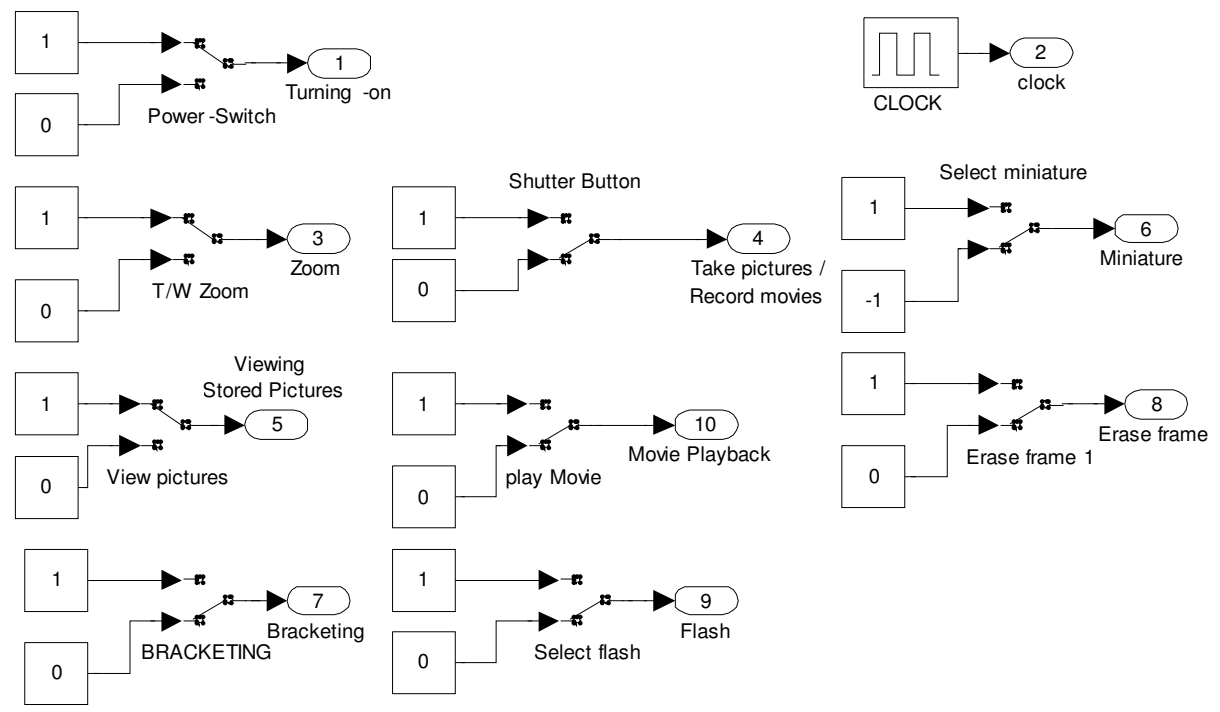

Fig. 21. Events.

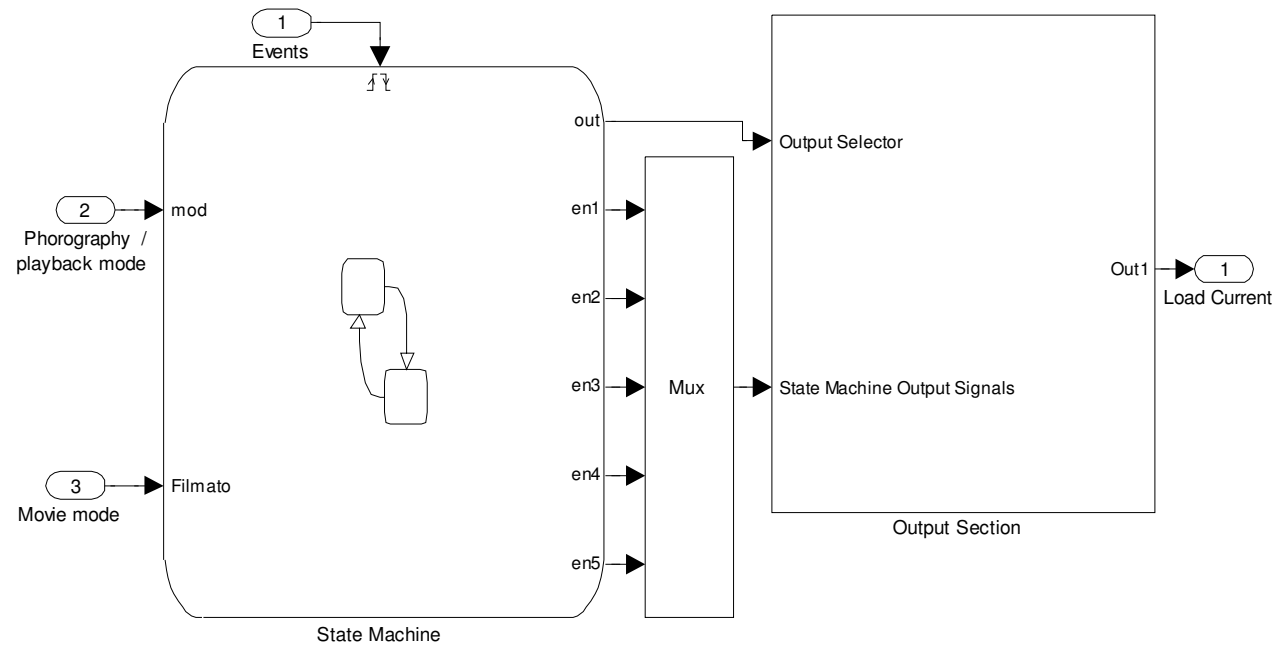

Fig. 22. The DSC subsystem.

A set of look-up tables (LUT) is included in the output section, as shown in Fig.23. Each LUT stores the current profile of a DSC function. The state diagram generates five control signals which are multiplexed in a control vector by the Mux block. In the output section, a decoder is fed by the control vector and generates the enable signals for LUTs. Only one enable signal at once is active. If a function is selected by user, the corresponding state in the state diagram is active and then the corresponding LUT in the output section is enabled and 
sequentially read. The output bus is connected to the active LUT output by the multiport switch which is driven by the output selector signal.

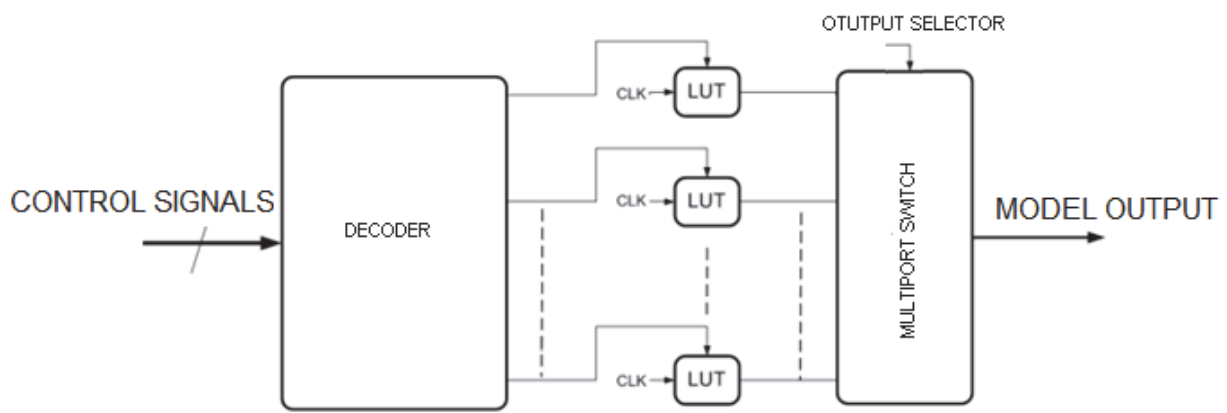

Fig. 23. The output section.

The state machine is modelled by the Stateflow toolbox. Only one state at once is enabled. Three standby modes of operation are available: playback, photography and movie mode. Each one could be maintained indefinitely active even if no function is selected by user. Each mode allows the user to select a limited number of functions. For example, under photography mode taking picture, bracketing, taking picture with flash are available while stored pictures could be viewed if the DSC is in playback mode only. Then, the state machine is intrinsically hierarchical. Fig.24 shows a schematic block diagram of the state machine. Under system start-up, the DSC is driven towards the OFF state by the default transition. No function is available in the OFF state and the output current is null. By double-clicking on the power switch button, the on_switch event is generated and the DSC is driven towards the ON state. The ON-state architecture is shown in Fig.25. Within the ON state, a decision point is set. The position of the mode selector enables playback or photography mode. Note that for the DSC under test, the movie mode is selected by acting on two manual selectors: the first is set on photography mode and the latter selects movie mode. The model reflects the operation of the DSC under test. Within each state, available functions are modelled as states. Authors suggest (Boscaino et al., 2008) for further details.

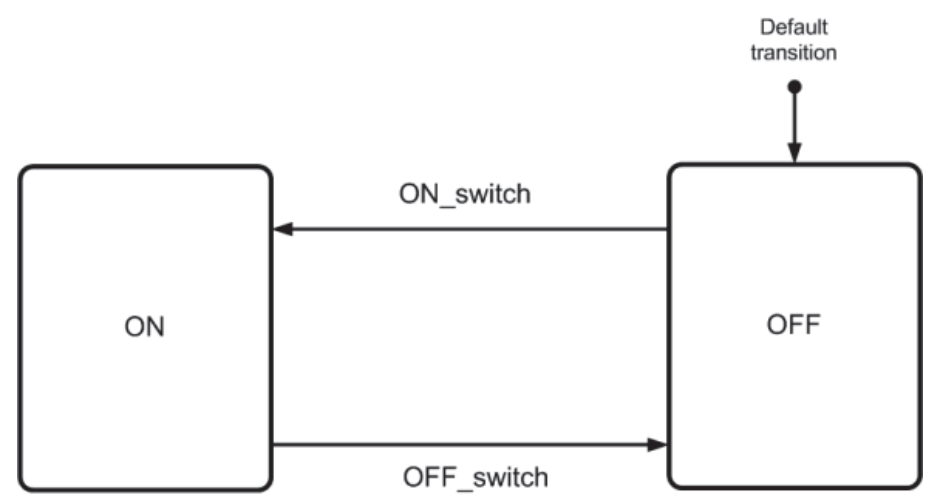

Fig. 24. A schematic block diagram of the DSC state machine. 




Fig. 25. The ON state architecture.

\subsection{PSIM schematic}

The active hybrid source and the power management system are modelled in PSIM environment. The stack current is directly controlled to improve dynamic performances. The fuel cell load is levelled by the power management system. The supercapacitor meets the load transient power demand, required for each function running while the fuel cell supplies the standby current of each available mode of the digital camera: playback, photography and movie mode. The equivalent fuel cell load is rather constant except for mode transitions of the DSC. Since the standby current required by the DSC depends on the selected mode of operation, a multiple steady-state control is applied. The fuel cell current is limited to the required stand-by current. Hence, the information about the actual DSC mode is required by the control system. The information is derived by a digital subsystem by monitoring the output voltage and comparing the last few samples.

Fig.26 shows the PSIM top level model. The DC-DC converter and supercapacitor bank are included in the Hybrid Source subsystem. The Control System is fed by the output voltage and the current sense signal. The output of the controller feeds the Driver subsystem which drives the synchronous buck MOSFETs. The Simulink model of the fuel cell reproduces the fuel cell voltage by sampling the fuel cell instantaneous current. In PSIM circuit, the fuel cell voltage is considered an input node from Simulink while the fuel cell current signal is an input signal for the Simulink model. Since Simulink input and output nodes behaviour as voltage sources, the fuel cell current is converted to a voltage signal by a current controlled voltage source which is included in the Hybrid source subsystem. The DSC model reproduces the current profile corresponding to the user-selected function. The load current signal is thus obtained by the Load Current Simulink input node. Since Simulink input nodes behaviour as voltage sources in PSIM schematics, the signal is converted to a current signal by the means of a voltage controlled current source. 


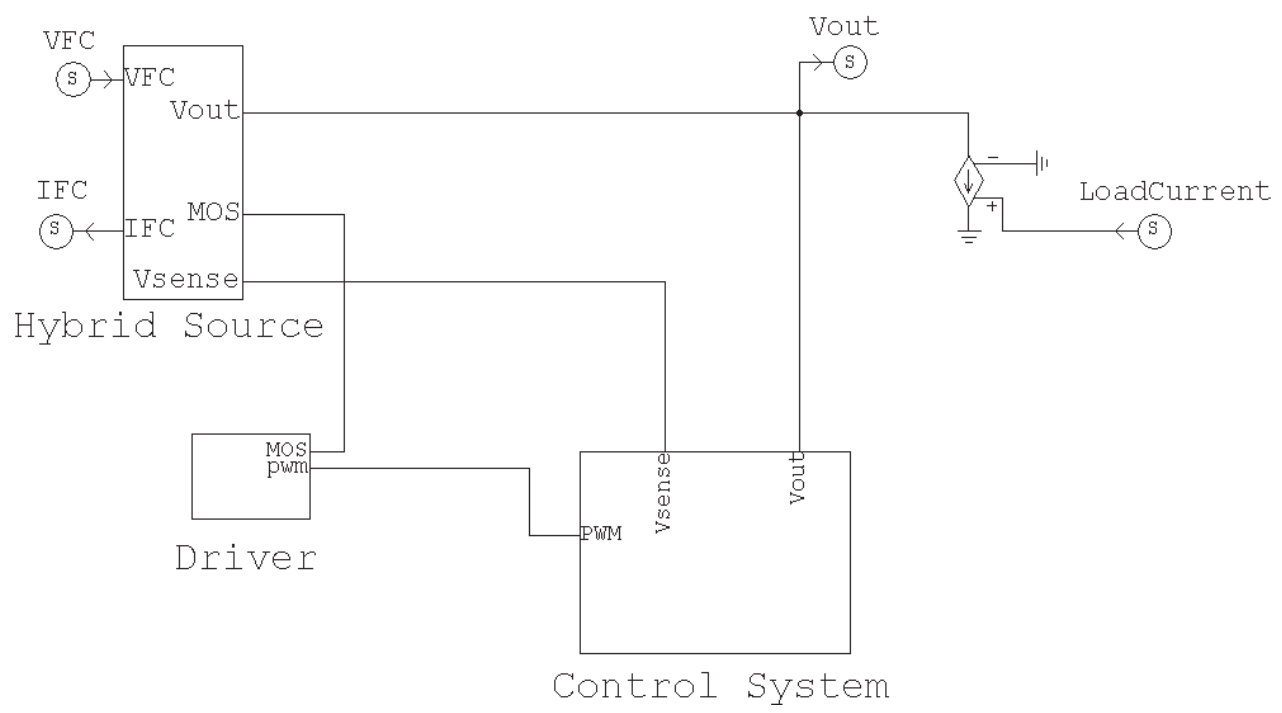

Fig. 26. The PSIM schematic.

Fig.27 shows the active hybrid source. The Fuel cell is connected in series with a buck converter and the supercapacitor bank. Even under the worst-case scenario, the supercapacitor should supply the load current under function transients avoiding any accidental turning-off of the electronic device. The supercapacitor value has been designed to ensure a negligible supercapacitor discharge under the worst-case obtaining a $4.6 \mathrm{~F}$ value. The load nominal voltage is $6 \mathrm{~V}$ while turning-off voltage is $4.2 \mathrm{~V}$. Since the maximum value of the supercapacitor voltage is $2.5 \mathrm{~V}$, three supercapacitors are connected in series to match the load nominal voltage. Two parallel branch of Maxwell PC5 and PC10 supercapacitors are connected. A charge balancing circuit is provided on the experimental prototype. Low ESR capacitors are necessary to limit the output voltage ripple avoiding high inductance values. A sense resistor is introduced to sense the instantaneous inductor current waveform generating the $\mathrm{V}_{\text {sense }}$ signal.

The control loop architecture is shown in Fig.28. The output voltage is controlled by a Pulse Width Modulation (PWM) control loop. The load levelling function is implemented by a current loop. If a DSC function is selected, the current loop limits the fuel cell current at the standby current value of the actual DSC mode of operation. For example, if bracketing is selected the DSC is in photography mode. The buck inductor current and hence the fuel cell current is limited at the photography standby current value by the current control loop. The pulsed current is supplied by the supercapacitor bank over the entire function runtime. Then, under function running the current loop is active and the current loop action must prevail over the voltage one. Further, the control loop should detect the mode of operation of the power load. The voltage reference subsystem detects the actual DSC mode generating the corresponding voltage reference of the current loop.

Error amplifiers are implemented as Transconductance Operational Amplifiers (OTA). The OTAs are modelled by elementary blocks of PSIM libraries. The differential input is modelled by an adder, the OTA gain is modelled by a multiplier and the linearity range is modelled by a signal limiter. 


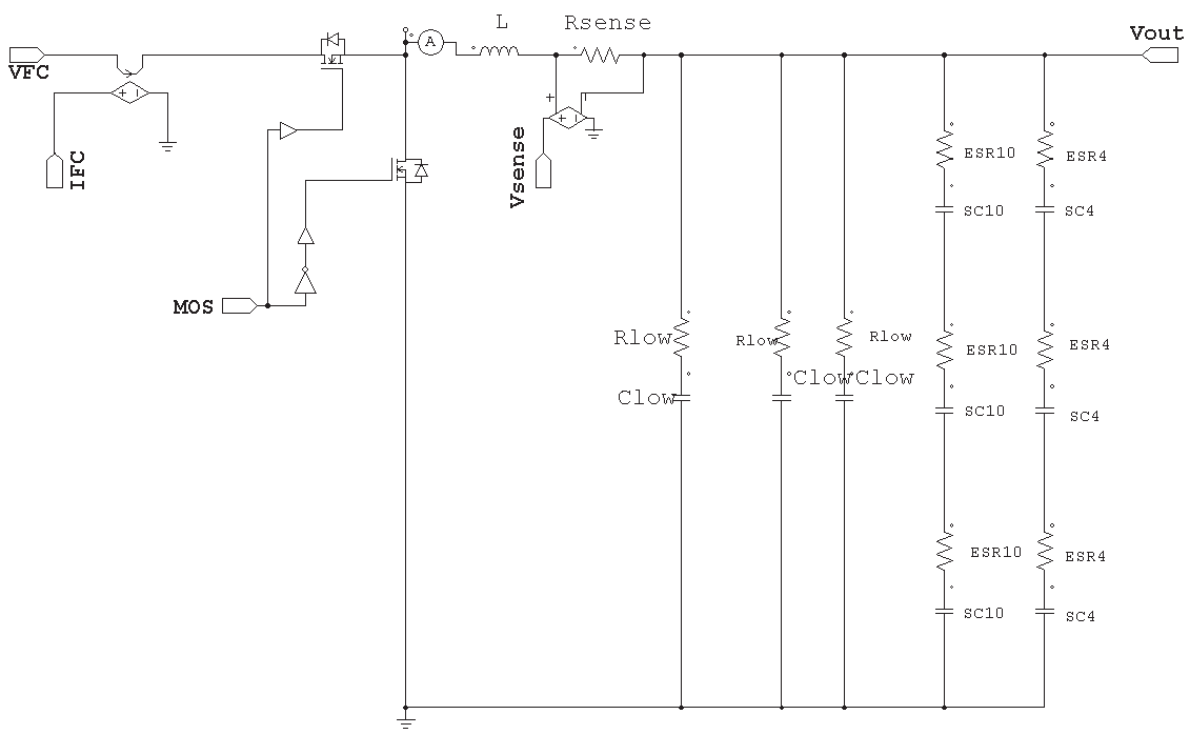

Fig. 27. The hybrid source model.

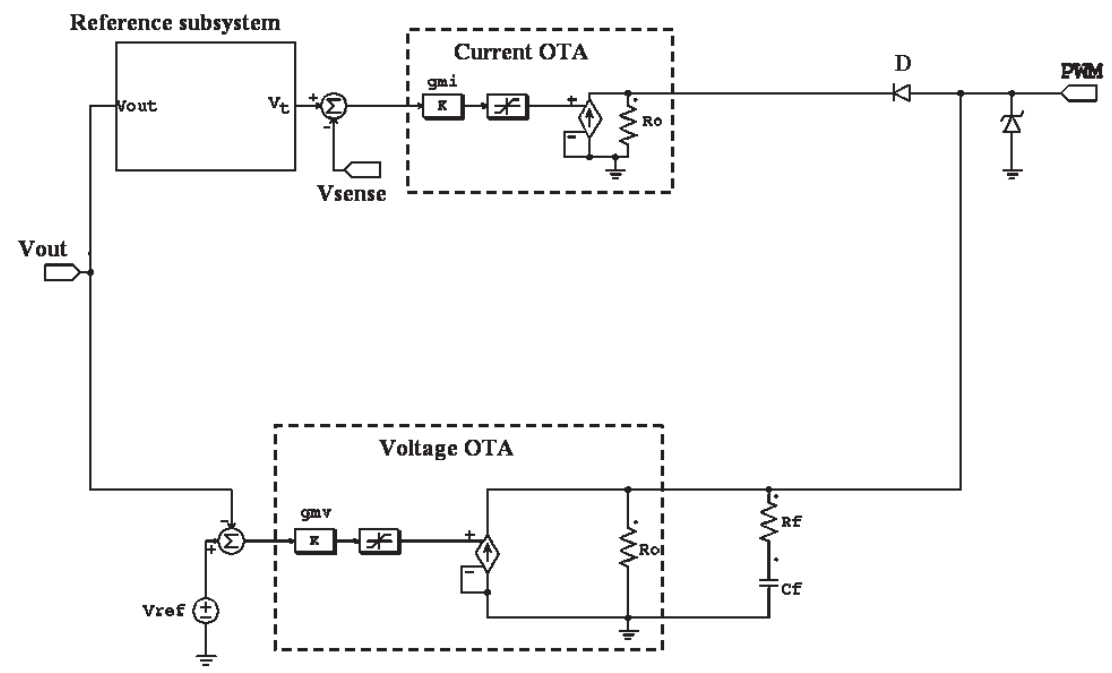

Fig. 28. The control subsystem.

The output current signal is obtained by a voltage controlled current source connected in parallel to the output resistance of the OTA. The compensation action is implemented by the RfCf network. Under steady-state condition, the inductor current is below the current limit and hence the cathode node of the diode D is tied to high-level. The diode D is turned-off. Under load transients, the inductor current tries to overcome the current limit, the cathode voltage is tied to lower level thus turning-on the diode $\mathrm{D}$. By a proper design of the control 
loop parameters, if the diode is turned-on the current loop action prevails over the voltage one. The interface diode turns on under the condition:

$$
I_{I} \cdot R_{0} \leq R_{0} \cdot I_{V}-V_{\gamma}
$$

where $\mathrm{V}_{Y}$ is the diode threshold voltage, $I_{I}$ is the current OTA output signal, $I v$ is the voltage OTA output signal. The turn on condition can be expressed as:

$$
g_{m, I} \cdot e_{I} \cdot R_{0} \leq g_{m, V} \cdot e_{V} \cdot R_{0}-V_{\gamma}
$$

where $e_{V}$ and $e_{I}$ are the voltage and current differential input signal, respectively, while $g_{m, I}$ and $g_{m, V}$ are the current and voltage OTA gains, respectively.

The current loop action should prevail over the voltage loop action even if the voltage loop is completely upset so ensuring the load levelling function. Hence, assuming the total upset of the voltage loop, the worst-case diode turning-on condition is given by:

$$
g_{m, I} \cdot e_{I} \cdot R_{0} \leq R_{0} \cdot I_{L I M}-V_{\gamma}
$$

where $\mathrm{I}_{\mathrm{LIM}}$ is the voltage loop OTA maximum output current and $e_{I}$ is the desired tolerance on current control. The tolerance is fixed at one half of the steady-state inductor current ripple to achieve a peak current control. The OTA gain of the current loop is designed to verify the (11). Under a load transient, the load current $\mathrm{I}_{\mathrm{LOAD}}$ exceeds the reference value $\mathrm{I}_{\mathrm{L}, \mathrm{th}}$. Hence, the inductor current is limited to $\mathrm{I}_{\mathrm{L}, \text { th }}$ and the current $\mathrm{I}=\mathrm{I}_{\mathrm{LOAD}}-\mathrm{I}_{\mathrm{L}, \text { th }}$ is supplied by the supercapacitor until the end of transient. Consequently, under a load transient the fuel cell current is maintained constant for hybrid power source optimization: the fuel cell supplies a constant load except for reference value changes. The OTA gain of the voltage loop is chosen by frequency domain analysis to ensure system stability and an adequate bandwidth.

The operating mode of the power load is detected by the reference subsystem by sampling the output voltage only. The reference subsystem is able to detect mode transitions neglecting function transients. Under function transients, the reference voltage is kept constant while under mode transients the voltage reference is adapted to the new mode of operation. Unlike mode transients, function transients feature a limited run time. The subsystem clock period is longer than the highest runtime and hence the control loop is insensitive to function transients.

Fig.29 shows the reference subsystem model which is implemented by logic gates. The output voltage sample is compared with two threshold levels, which are accurately designed to prevent an excessive discharge. Information about the instantaneous charge state of the supercapacitor bank is obtained. The output voltage sample is coded by the logic signals up, mid and down: up is active if the output voltage is over both levels, mid if the sample is in the middle, down if the output voltage is lower than the lowest level. By comparing the two last samples of binary signals, the charge process is monitored and the DSC mode is detected.

Four possible steady-states, coded by s1 and s2 bits, are provided: $240 \mathrm{~mA}$, corresponding to DSC playback mode standby power consumption, $390 \mathrm{~mA}$, corresponding to DSC photography mode standby power consumption, $480 \mathrm{~mA}$, corresponding to DSC movie mode standby power consumption, $700 \mathrm{~mA}$, corresponding to a safety state. If an excessive supercapacitor discharge occurs, the safety state will prevent any accidental DSC turningoff. Four possible actions, coded by $a$ and $b$ bits, are provided: increase by one, increase by 
two, decrease by one and keep constant the reference voltage. The subsystem decides which action should be performed on the voltage reference. The new voltage reference bits are determined by the old reference bits and by the action bits. The reference bits feed a digitalto-analog converter which outputs the analog voltage reference value. The proposed algorithm reproduces information about the DSC state by monitoring the charge and discharge profile of the supercapacitor bank. The PWM control technique is implemented within the Driver subsystem shown in Fig.30. The error signal is compared with the external saw-tooth voltage $V_{\text {ramp }}$ and the PWM signal is generated. The PWM signal and the clock signal feed the D flip-flop with asynchronous reset input which generates the driver signal for both MOSFET gates of the buck converter. Authors suggest (Boscaino et al., 2009a) for further details.

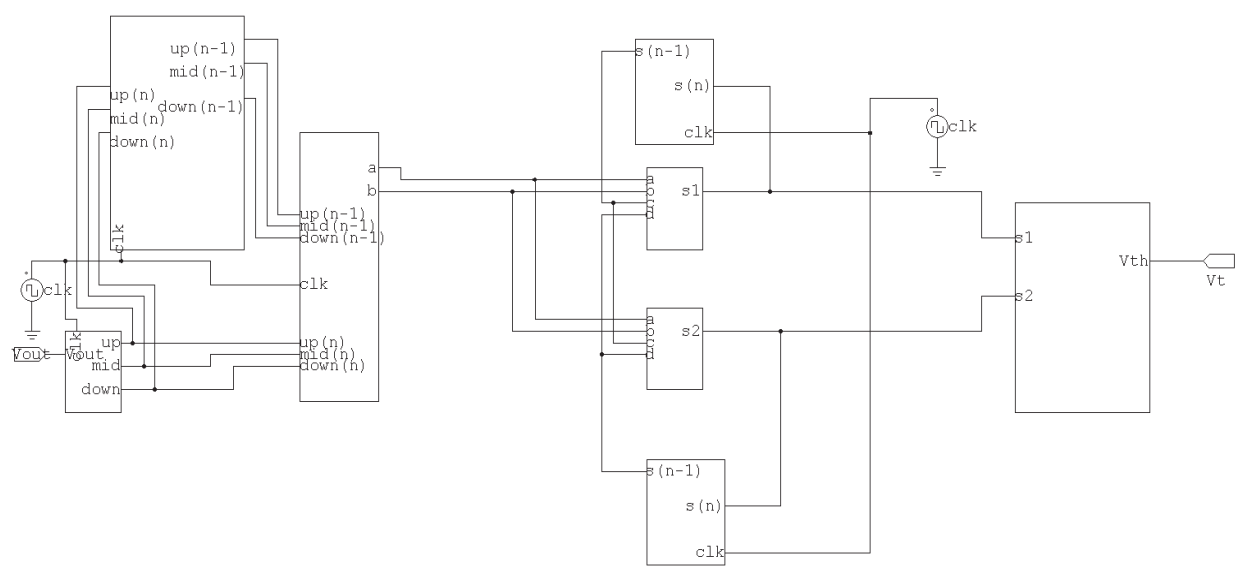

Fig. 29. The reference subsystem.

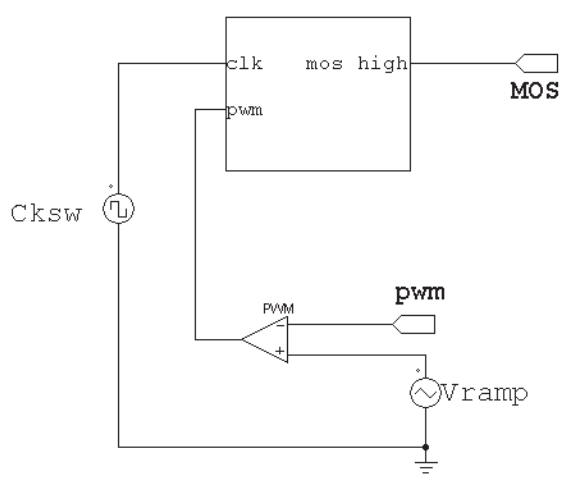

Fig. 30. The driver subsystem. 


\section{Simulation and experimental results}

The efficiency and accuracy of the proposed simulation set-up is confirmed by the comparison between simulation and experimental results. Simulation results accurately match experimental ones. The output voltage profile depends not only on the selected function but above all on the "history" of the power supply system since the turning-on. Yet, the system is tested since the simulation step with the effective load consumption profile. Long-time simulation tests are performed to show the robustness of the power management algorithms. The system prevents any accidental turning-off of the digital still camera improving the hybrid source performances. The hybrid source features the same dynamic response of the supercapacitor bank under pulsed current profile, the life cycle is closely related to the hydrogen reserve and quite independent of the supercapacitor state of charge. After all, the hybrid source features the high power capability of the supercapacitor bank and the high energy capability of the fuel cell. The performances of the hybrid source are not affected by drawbacks of both primary sources. The inductor current and the output voltage waveforms under no-load conditions are shown in Fig.31. The output voltage is controlled by the voltage loop while the current loop is not active.

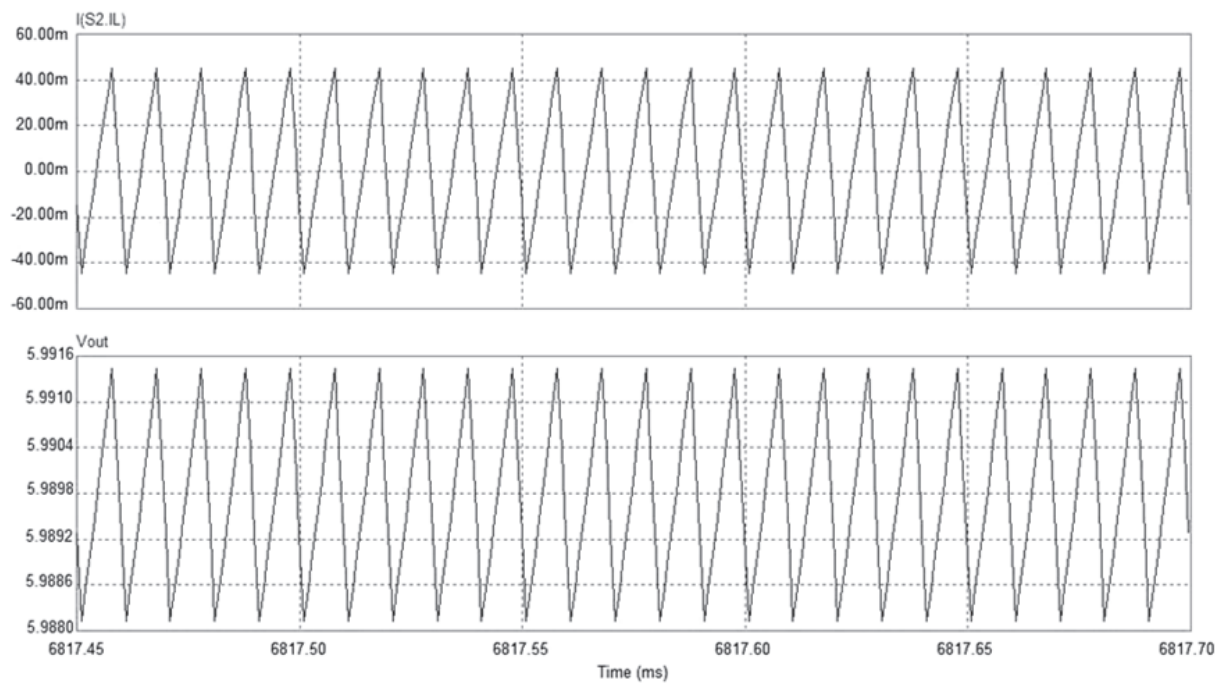

Fig. 31. At the top the inductor current, at the bottom the output voltage waveforms under no-load conditions.

The inductor current and the interface diode current waveforms under current loop limitation are shown in Fig.32 the current limit is fixed at $240 \mathrm{~mA}$, corresponding to the playback mode of operation. When the inductor current overcomes the $210 \mathrm{~mA}$ limit, the interface diode is forced into conduction. The tolerance on the current control is $30 \mathrm{~mA}$ within the tolerance window of $40 \mathrm{~mA}$ designed by (11).

Simulation results under turning-on in photography mode are shown to better understand the efficiency of the designed control algorithm. Turning-on in photography mode is a critical transient since the transient time is quite long and peak current value is higher and higher than the average value. Figures from 33 to 36 show the system behaviour under the 
turning-on function. Take a look to the evolution of the system from start-up till the end of transient. At the top, the pulsed current load and the inductor current, at the bottom the output voltage waveforms are shown. Under start-up conditions, the system starts at the lowest threshold value corresponding to the playback mode $(240 \mathrm{~mA})$. Yet, the digital camera is turned-on in photography mode corresponding to a higher current limit $(390 \mathrm{~mA})$. The fuel cell supplies the standby current of the playback mode while the pulsed current is supplied by the supercapacitor bank, as shown in Fig.33.The turning-on function in photography mode lasts $4.6 \mathrm{~s}$. Until the effective mode of operation is detected, the inductor current is limited to the playback mode current threshold, as shown in Fig.33. In the intermediate part of the function transient the main peak of the load current is entirely supplied by the supercapacitor, as shown in Fig.34. The supercapacitor bank is constantly discharged. Even under stress, the output voltage does not drop below the turning-off limit, which is equal to $4.2 \mathrm{~V}$, thanks to an accurate design of the power stage. Fig. 35 shows the system behaviour under the last part of the turning on function, corresponding to the lens movement. The inductor current is already limited at the playback mode current limit. At the end of turning-on in photography mode, the actual mode of operation is detected by the reference subsystem as shown by Fig.36. The inductor current limit is increased up to the photography mode standby current value. No function is actually selected by the end-user. The standby current of the photography mode is supplied by the fuel cell thus interrupting the supercapacitor discharge. The safety state is not reached since no excessive discharge has been detected by the reference subsystem.

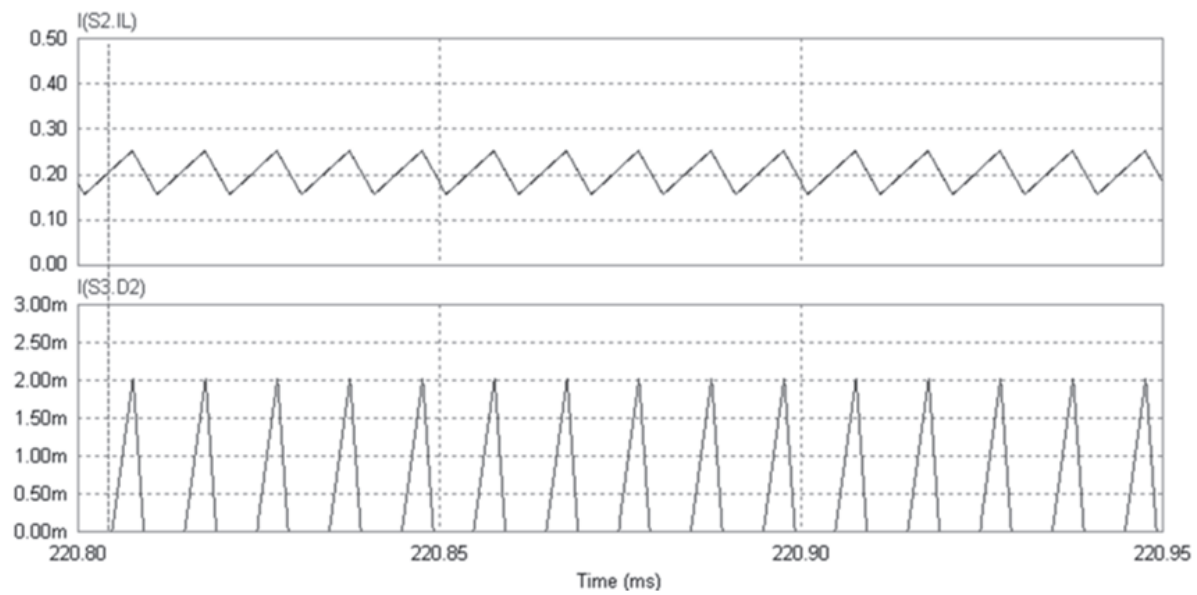

Fig. 32. At the top the inductor current, at the bottom the diode current waveforms under current limitation.

Experimental results under turning-on in photography mode are shown in Fig.37. The output voltage $(\mathrm{C} 1,1 \mathrm{~V} /$ div), the load current $(\mathrm{C} 2,200 \mathrm{~mA} /$ div $)$ and the inductor current $(\mathrm{C} 3,200 \mathrm{~mA} / \mathrm{div})$ are shown. Time base is fixed at $2 \mathrm{~s} / \mathrm{div}$. As shown by simulation results, the system does not detect the actual mode of operation until the end of transient. Hence, the transient current is supplied by the supercapacitor bank while the standby current is supplied by the fuel cell. Then, the actual mode is detected and the current limit is increased. 


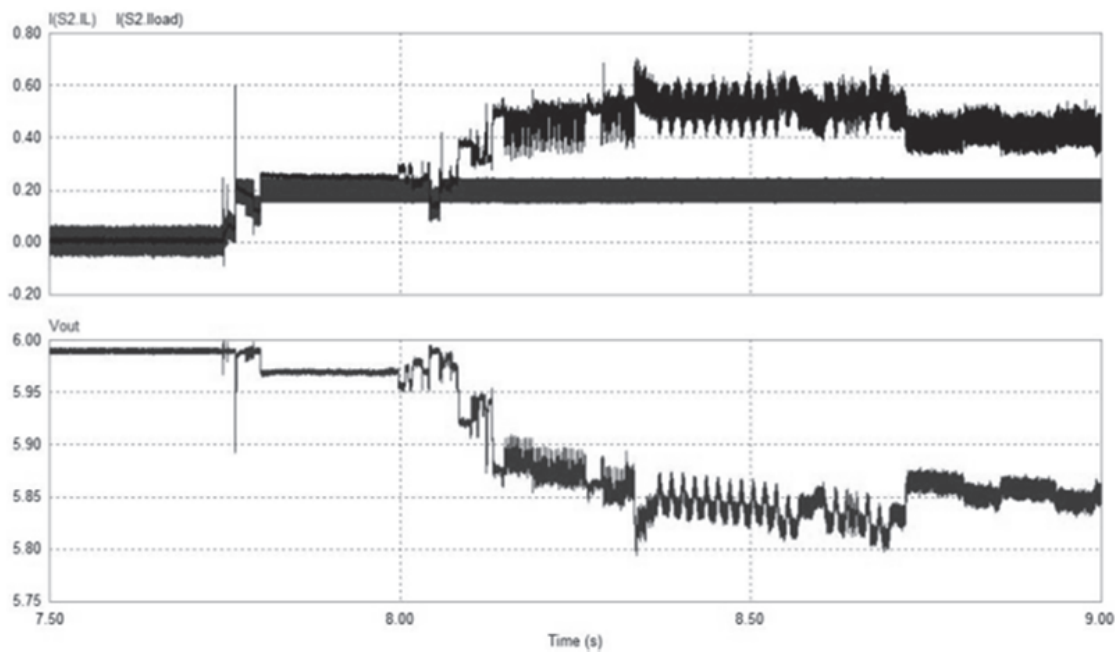

Fig. 33. Simulation results under turning-on in photography mode. At the top the pulsed load current and the inductor current, at the bottom the output voltage waveforms at the beginning of function transient are shown. The system starts at playback mode current limit and the actual state is not yet detected.



Fig. 34. Simulation results under turning-on in photography mode, intermediate part of function transient. At the top the pulsed load current and the inductor current, at the bottom the output voltage waveforms during the peak power consumption are shown. The DSC state is not yet detected. 




Fig. 35. Simulation results under turning-on in photography mode. At the top the pulsed load current and the inductor current, at the bottom the output voltage waveforms during at the end of function transient are shown. The actual state is not yet detected.
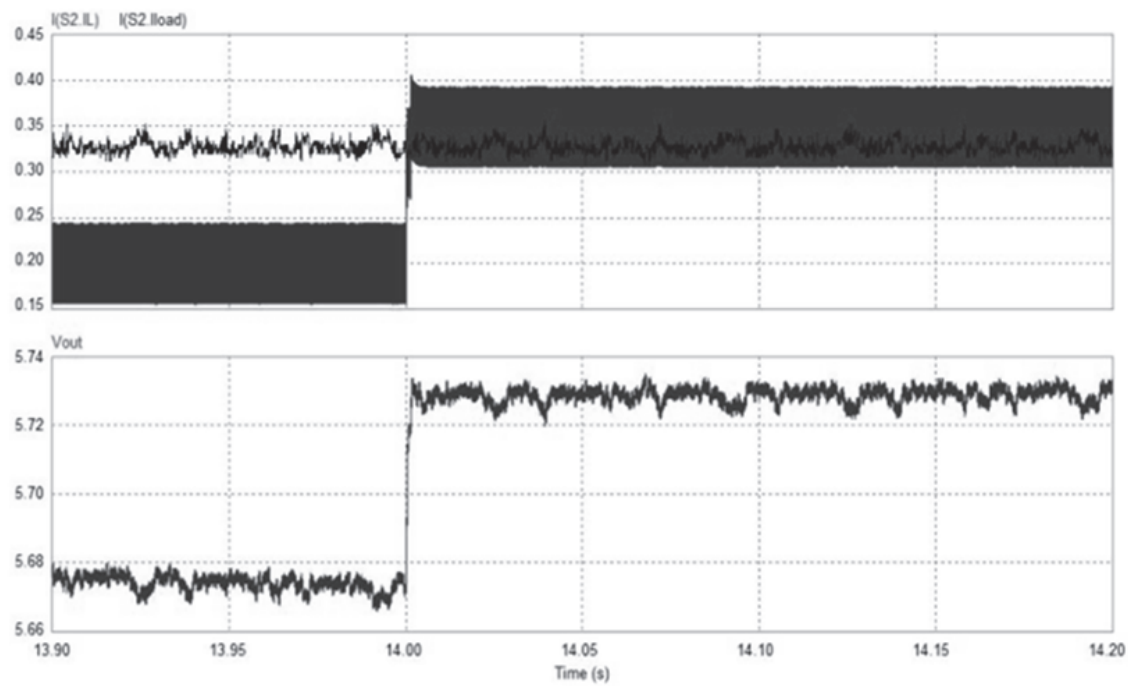

Fig. 36. Simulation results after turning on in photography mode. At the top the pulsed load current and the inductor current, at the bottom the output voltage waveforms are shown. The DSC state is detected and the current threshold is increased to allow the supercapacitor recharge. 
Note that the instant at which the reference subsystem detects the actual DSC mode of operation is not related to the transient itself but above all on the history of the system since the start-up condition. Experimental results under turning-on in photography mode in the worst-case are shown in Fig.37. In this case, the actual mode of operation is detected after the end of transient. In Fig. 38, the actual mode of operation is detected before the end of transient. The discharge of the supercapacitor is thus limited to the beginning of the function transient.



Fig. 37. Experimental results under turning on in photography mode. The DSC state is detected at the end of function transient. On $\mathrm{C} 1$ the output voltage $(1 \mathrm{~V} / \mathrm{div})$, on $\mathrm{C} 2$ the load current (200mA/div), on C3 the inductor current (200mA/div) are shown. Time base is set at $2 \mathrm{~s} / \mathrm{div}$.

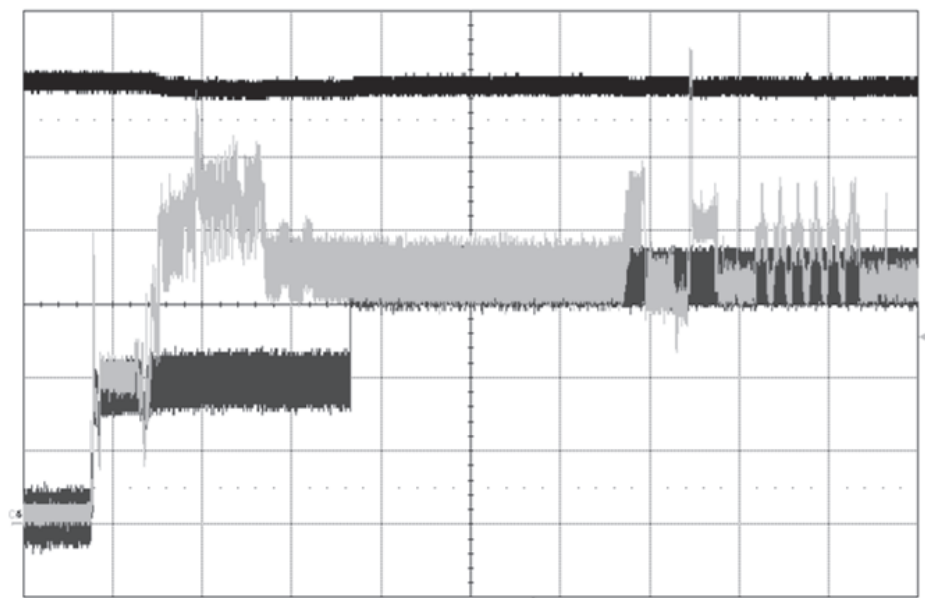

Fig. 38. Experimental results under turning on in photography mode. In this case the actual mode is detected before the end of transient. On $\mathrm{C} 1$ the output voltage $(1 \mathrm{~V} / \mathrm{div})$, on $\mathrm{C} 2$ the load current $(200 \mathrm{~mA} / \mathrm{div})$, on C 3 the inductor current $(200 \mathrm{~mA} / \mathrm{div})$ are shown. Time base is set at $2 \mathrm{~s} /$ div. 
In Fig.39 simulation results under bracketing function are shown. At the top, the pulsed load current and the buck inductor current are shown. At the bottom, the output voltage is shown. The inductor current which is a scaled version of the fuel cell current is limited at the photography stand-by current limit over the entire transient time. The fuel cell supplies the standby current of the actual DSC mode of operation while the supercapacitor bank supplies the instantaneous peak power. The output voltage is affected by the supercapacitor discharge. Yet, any accidental turning-off is avoided thanks to the accurate design of the power stage. Further, if no-function is selected by user the supercapacitor bank will be recharged driving back the system to the nominal working conditions.

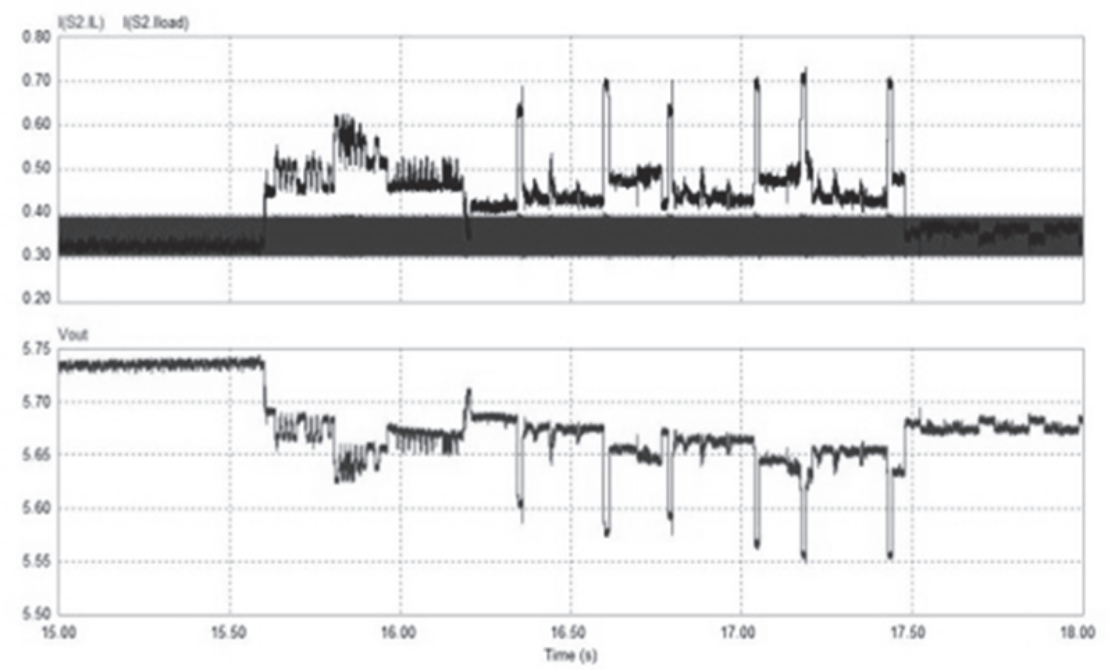

Fig. 39. Simulation results under bracketing function. At the top the pulsed load current and the inductor current, at the bottom the output voltage waveforms are shown.

Fig.40 shows simulation results under bracketing function. In this case, the system has not yet detected the actual mode of operation of the DSC. At the top the pulsed load current and the inductor current, at the bottom the output voltage waveforms are shown. The system is still in playback mode and the inductor current is limited to $240 \mathrm{~mA}$, lower and lower than the actual standby current. This is the worst-case for bracketing function. The fuel cell supplies the playback mode current while the supercapacitor is heavily discharged supplying both the pulsed current and the difference between the photography and playback standby currents. Yet, the discharge is not yet critical for the DSC working. Note that this condition is closely related to the history of the system.

Experimental results under bracketing function are shown in Fig.41. The output voltage $(\mathrm{C} 1$, $1 \mathrm{~V} /$ div $)$, the load current $(\mathrm{C} 2,200 \mathrm{~mA} /$ div $)$ and the inductor current $(\mathrm{C} 4,200 \mathrm{~mA} /$ div $)$ are shown. The time base is fixed at $500 \mathrm{~ms} /$ div. Note the high accuracy of simulation results. The DSC current profile is accurately reproduced allowing the designer to test the control algorithms as closely as possible to the effective system behaviour. Since specific hybrid source features as life-cycle and transient response are directly controlled, high accuracy 
modelling is a key step to achieve high-efficiency power management control algorithms. As expected by the performed behavioural simulations, experimental results confirm the high efficiency of the implemented algorithms.

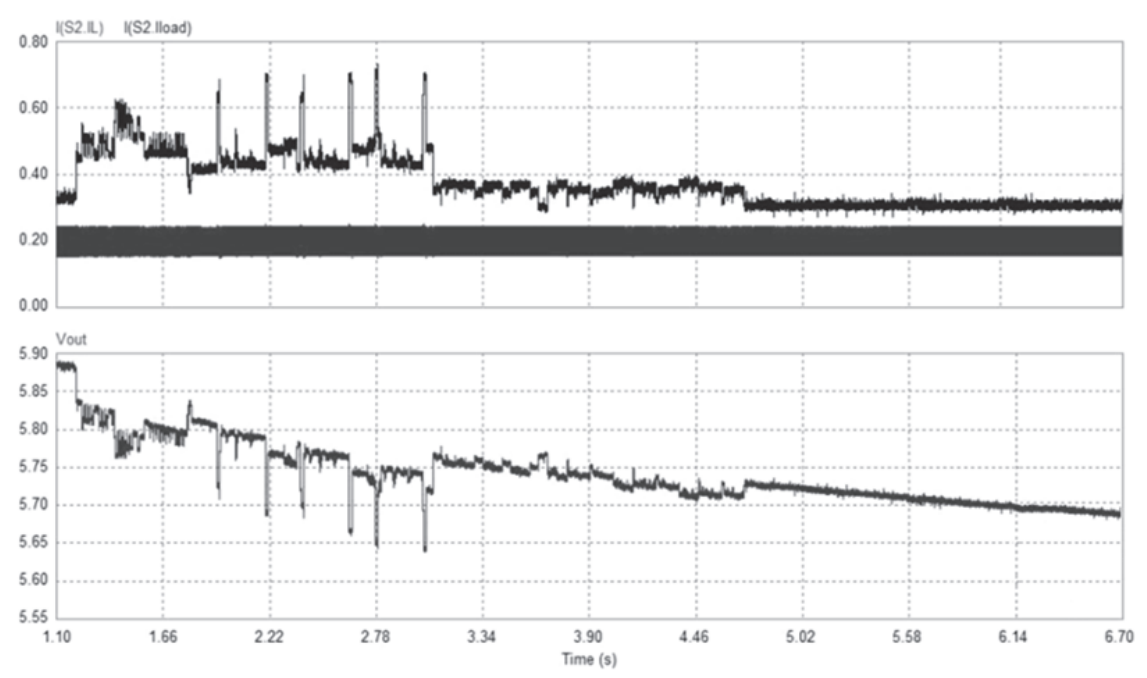

Fig. 40. Simulation results under bracketing function. The actual mode is not yet detected and the playback mode current limit is active. At the top the pulsed load current and the inductor current, at the bottom the output voltage waveforms are shown.

Simulation results under zoom function in playback mode are shown in Fig.42. At the top, the pulsed load current and the buck inductor current are shown. At the bottom, the output voltage is shown. The zoom function is not a critical function for the hybrid power supply. The inductor current is limited at the playback mode threshold. At the end of the transient time, the output voltage reaches again the nominal value. The net discharge of the supercapacitor bank could be neglected under the selected function running. The fuel cell supplies the standby current of the actual DSC mode of operation while the supercapacitor bank supplies the instantaneous peak power.

Fig.43 shows simulation results under multiple execution of zoom function in playback mode. At the top, the pulsed load current and the inductor current, at the bottom the output voltage waveforms are shown. In this case, the system has previously detected an excessive discharge of the supercapacitor bank. The current limit has been previously increased up to the movie mode threshold to allow a fast recharge. Yet, zoom function is actually selected by user and repeated several times. Note that in this case, the recharge is supplied by the fuel cell itself. The net recharge current is equal to the difference between the limited inductor current and the load current.

Experimental results under zoom function are shown in Fig.44. The output voltage $(\mathrm{C} 1$, $1 \mathrm{~V} /$ div), the load current $(\mathrm{C} 2,200 \mathrm{~mA} /$ div $)$ and the inductor current $(\mathrm{C} 3,100 \mathrm{~mA} / \mathrm{div})$ are shown. Time base is set to $20 \mathrm{~ms} / \mathrm{div}$. As expected by simulation results, the output voltage is not affected by the zoom running. 


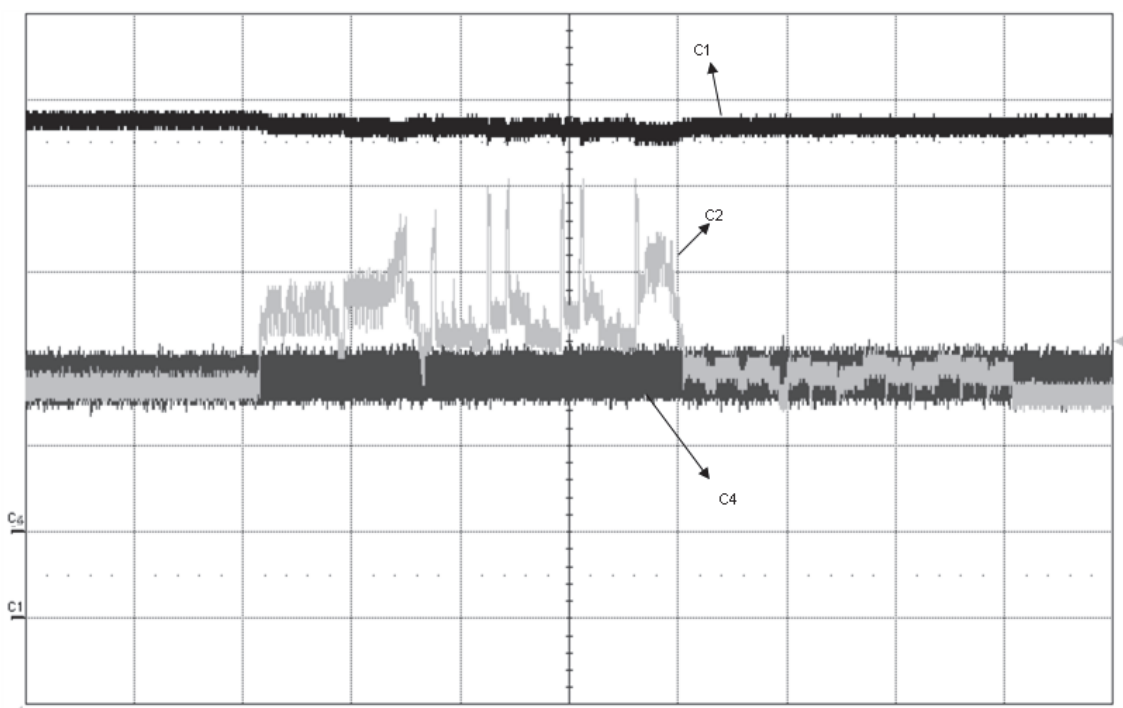

Fig. 41. Experimental results under bracketing function. The output voltage (C1, $1 \mathrm{~V} / \mathrm{div})$, the load current $(\mathrm{C} 2,200 \mathrm{~mA} /$ div $)$, the buck inductor current $(\mathrm{C} 4,200 \mathrm{~mA} /$ div $)$ are shown. Time base is set to $500 \mathrm{~ms} /$ div.

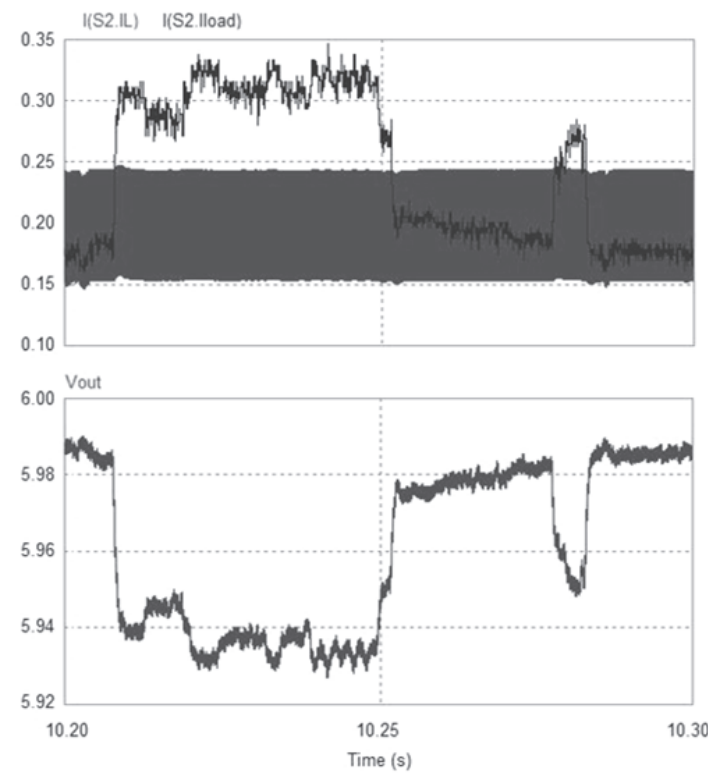

Fig. 42. Simulation results under zoom function in playback mode. At the top, the pulsed load current and the inductor current, at the bottom the output voltage waveforms are shown. 


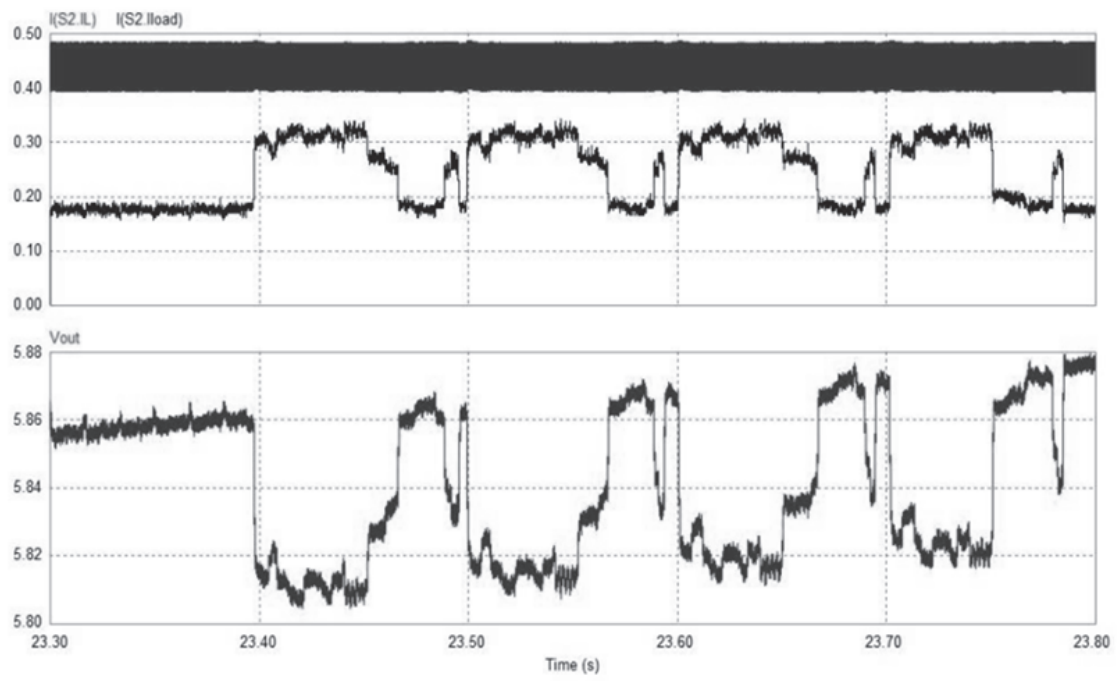

Fig. 43. Simulation results under zoom function in playback mode. The current limit is higher than the playback mode threshold to allow a fast recharge of the supercapacitor bank. At the top, the pulsed load current and the inductor current, at the bottom the output voltage waveforms are shown.

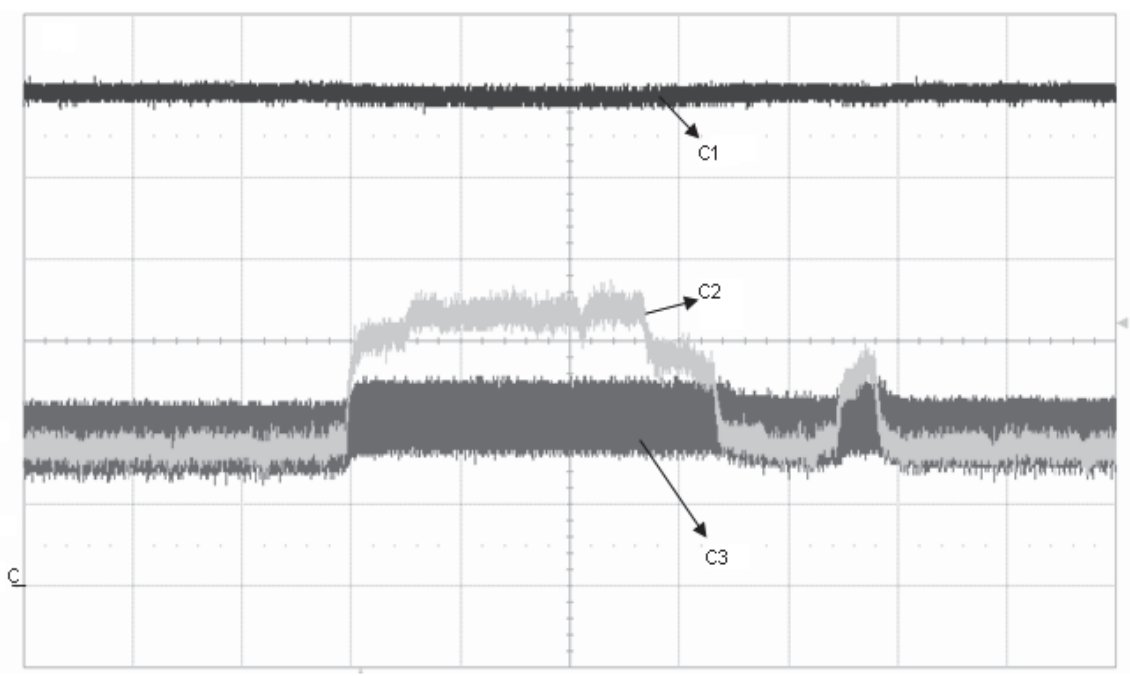

Fig. 44. Experimental results under zoom function in playback mode. The output voltage $(\mathrm{C} 1,1 \mathrm{~V} /$ div), the load current $(\mathrm{C} 2,200 \mathrm{~mA} /$ div $)$, the buck inductor current $(\mathrm{C} 3,100 \mathrm{~mA} / \mathrm{div})$ are shown. Time base is set to $20 \mathrm{~ms} /$ div. 


\section{Conclusion}

In this chapter, a high accuracy simulation set-up for hybrid power supplies is proposed. As an example, a fuel cell-supercapacitor hybrid power supply for a digital still camera is designed and tested. The system is modelled and tested in Simulink environment with the aid of SimCoupler Module for PSIM/Matlab co-simulation. The power management controller is implemented in PSIM environment while the fuel cell and the power load are accurately modelled by the means of Simulink library elements. A laboratory prototype has been realized and tested. Simulation results accurately match experimental results, highlighting the high efficiency of the proposed technique. The proposed modelling approach is suitable for each power supply system thanks to the powerful tools available in Matlab suite. Thanks to the powerful modelling approach, the need of a warm-up phase is highlighted since the simulation step. The fuel cell temperature has to be increased up to $40^{\circ} \mathrm{C}$ before the system start-up. Authors are working on an innovative power management system which overcomes this drawback by controlling the fuel cell temperature under start-up conditions.

The modelling approach is still a key design tool.

\section{Acknowledgement}

Authors would like to thank ST Microelectronics for supporting the research activity.

\section{References}

Alotto, P., Guarnieri, M. \& Moro, F. (2008). Modelling and control of fuel cell-battery hybrid power systems for portable electronics. Proceedings of IEEE Universities Power Engineering Conference, ISBN: 978-1-4244-3294-3, Padova, Italy, December 2008.

Boscaino, V., Capponi G., Livreri, P. \& Marino, F. (2008). Measurement-based load modelling for power supply system design, Proceedings of IEEE International Conference on Control and modelling for Power Electronics, ISBN: 978-1-4244-2550-1, Zürich, Switzerland, August 2008.

Boscaino, V., Capponi G. \& Marino, F.(2009a). Experimental test on a fuel cellsupercapacitor hybrid power supply for a digital still camera, Proceedings of IEEE Universities Power Engineering Conference, ISBN: 978-1-4244-6823-2, Glasgow, Scotland, Sept. 2009.

Boscaino, V., Capponi, G. \& Marino, F. (2009b). A steady-state and dynamic fuel cell model including temperature effects. Proceedings of IEEE International Conference on Industrial Electronics, ISBN: 978-1-4244-4648-3, Porto, Portugal, November 2009.

Gao L., \& Dougal, R.A. (2003). Active Power Sharing in Hybrid Battery/Capacitor Power Sources. Proceedings of Applied Power Electronics Conference and Exposition, ISBN: 0-78037768-0, Miami, Florida, February 2003. 
Lin, C.J., Chen, A.Y.T., Chiou, C.Y., Huang, C.H., Chiang, H.D. , Wang, J.C. \& Fekih-Ahmed, L.(1993). Dynamic load models in power systems using the measurement approach. IEEE Transactions on Power Systems, vol. 8, no. 1, (February 2003), pp. 309-315, ISSN: 0885-8950. 


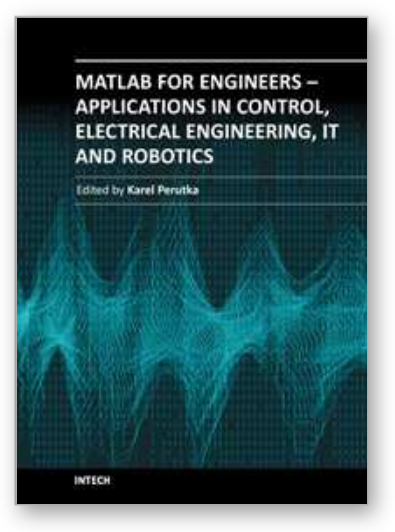

\section{MATLAB for Engineers - Applications in Control, Electrical Engineering, IT and Robotics}

Edited by Dr. Karel Perutka

ISBN 978-953-307-914-1

Hard cover, 512 pages

Publisher InTech

Published online 13, October, 2011

Published in print edition October, 2011

The book presents several approaches in the key areas of practice for which the MATLAB software package was used. Topics covered include applications for: -Motors -Power systems -Robots -Vehicles The rapid development of technology impacts all areas. Authors of the book chapters, who are experts in their field, present interesting solutions of their work. The book will familiarize the readers with the solutions and enable the readers to enlarge them by their own research. It will be of great interest to control and electrical engineers and students in the fields of research the book covers.

\section{How to reference}

In order to correctly reference this scholarly work, feel free to copy and paste the following:

Valeria Boscaino and Giuseppe Capponi (2011). High Accuracy Modelling of Hybrid Power Supplies, MATLAB for Engineers - Applications in Control, Electrical Engineering, IT and Robotics, Dr. Karel Perutka (Ed.), ISBN: 978-953-307-914-1, InTech, Available from: http://www.intechopen.com/books/matlab-for-engineersapplications-in-control-electrical-engineering-it-and-robotics/high-accuracy-modelling-of-hybrid-power-supplies

\section{INTECH}

open science | open minds

\section{InTech Europe}

University Campus STeP Ri

Slavka Krautzeka 83/A

51000 Rijeka, Croatia

Phone: +385 (51) 770447

Fax: +385 (51) 686166

www.intechopen.com

\section{InTech China}

Unit 405, Office Block, Hotel Equatorial Shanghai

No.65, Yan An Road (West), Shanghai, 200040, China

中国上海市延安西路65号上海国际贵都大饭店办公楼 405 单元

Phone: +86-21-62489820

Fax: +86-21-62489821 
(C) 2011 The Author(s). Licensee IntechOpen. This is an open access article distributed under the terms of the Creative Commons Attribution 3.0 License, which permits unrestricted use, distribution, and reproduction in any medium, provided the original work is properly cited. 